\title{
Tuning Into A New Paradigm: COMMUNITY RADIO IN RWANDA
}

\author{
by \\ Janna Graham
}

\author{
A thesis submitted to \\ the Faculty of Graduate Studies and Research \\ in partial fulfillment of \\ the requirements for the degree of \\ Master of Journalism
}

School of Journalism \& Communication

Carleton University

Ottawa, Ontario

28 September 2008

(C) copyright

2008, Janna Graham 


$\begin{array}{ll}\begin{array}{l}\text { Library and } \\ \text { Archives Canada }\end{array} & \begin{array}{l}\text { Bibliothèque et } \\ \text { Archives Canada }\end{array} \\ \begin{array}{l}\text { Published Heritage } \\ \text { Branch }\end{array} & \begin{array}{l}\text { Direction du } \\ \text { Patrimoine de l'édition }\end{array} \\ \begin{array}{l}\text { 395 Wellington Street } \\ \text { Ottawa ON K1A 0N4 } \\ \text { Canada }\end{array} & \begin{array}{l}\text { 395, rue Wellington } \\ \text { Ottawa ON K1A 0N4 } \\ \text { Canada }\end{array}\end{array}$

Your file Votre référence ISBN: 978-0-494-47529-4

Our file Notre référence

ISBN: 978-0-494-47529-4

NOTICE:

The author has granted a nonexclusive license allowing Library and Archives Canada to reproduce, publish, archive, preserve, conserve, communicate to the public by telecommunication or on the Internet, loan, distribute and sell theses worldwide, for commercial or noncommercial purposes, in microform, paper, electronic and/or any other formats.

The author retains copyright ownership and moral rights in this thesis. Neither the thesis nor substantial extracts from it may be printed or otherwise reproduced without the author's permission.
AVIS:

L'auteur a accordé une licence non exclusive permettant à la Bibliothèque et Archives Canada de reproduire, publier, archiver, sauvegarder, conserver, transmettre au public par télécommunication ou par l'Internet, prêter, distribuer et vendre des thèses partout dans le monde, à des fins commerciales ou autres, sur support microforme, papier, électronique et/ou autres formats.

L'auteur conserve la propriété du droit d'auteur et des droits moraux qui protège cette thèse. $\mathrm{Ni}$ la thèse ni des extraits substantiels de celle-ci ne doivent être imprimés ou autrement reproduits sans son autorisation.
In compliance with the Canadian Privacy Act some supporting forms may have been removed from this thesis.

While these forms may be included in the document page count, their removal does not represent any loss of content from the thesis.
Conformément à la loi canadienne sur la protection de la vie privée, quelques formulaires secondaires ont été enlevés de cette thèse.

Bien que ces formulaires aient inclus dans la pagination, il n'y aura aucun contenu manquant.

\section{Canada}




\section{ABSTRACT}

This study investigates how Radio Salus developed to train student journalists and as an alternative voice on Rwandan airwaves. Emerging from the context of the genocide, Salus represents a unique model in the international community radio sector. A review of the historical, political, social and regulatory context in which community radio emerged in North America is followed by discussion of dominant branches of communication theory, linked to community radio's international role. An overview of radio's history as a development media in Africa leads to a look at the role of radio in Rwanda before, during and after the 1994 genocide. A profile of Radio Salus then draws on field research in November 2007 and July 2008. The conclusion discusses Radio Salus's future as an inclusive, community-based radio station. Adopting a participatory community of practice model may offer Salus a framework to build on station training and skills development. 


\section{ACKNOWLEGEMENTS}

I wish to express sincere thanks to Dave Tait, my thesis supervisor, and patient mentor for enthusiastically walking me through an exhausting number of ideas that seized me as I waded through my master of journalism. His passion for teaching journalism is inspiring.

Thank you to everyone at Radio Salus for participating in my interviews and for making me feel at home. A special shout out to the Saturday Morning Reports team!

Thanks for support through the writing process: Buzz and KLP; Steve Millar; Dave Waddington; Simon and Cristina; Freya Zaltz; Melissa Kaestner; Kathy Large; Shelley Robinson; Michael Urbanski; Chris Cwynar; Jjuko; Annette MacIntyre; Mom, Dad and Doug.

I am grateful to the International Research Development Council (IDRC) International Development Journalism fund for the opportunity to pursue research in Rwanda.

Finally, I wish to thank Thomas Young, who was a constant companion and an unwavering supporter throughout this long, strange trip. 


\section{TABLE OF CONTENTS}

Abstract ii

Acknowledgements iii

Table of Contents iv

Preface $\quad$ V

I: INTRODUCTION 1

II: COMMUNITY RADIO OVERVIEW 9

The Battle for Low Power Radio in the United States 13

$\begin{array}{ll}\text { The Canadian Low Power Experience } & 19\end{array}$

$\begin{array}{ll}\text { Further Defining Community radio } & 27\end{array}$

Branches of Development Communication 31

$\begin{array}{ll}\text { Summary } & 47\end{array}$

III: RADIO IN AFRICA $\quad 49$

Radio in Rwanda $\quad 58$

$\begin{array}{ll}\text { Community Radio in Rwanda } & 72\end{array}$

Summary $\quad 74$

IV: RADIO SALUS

Salus Organization $\quad 81$

$\begin{array}{lr}\text { Staff, Students and Training } & 84\end{array}$

$\begin{array}{ll}\text { Summary } & 102\end{array}$

$\mathrm{V}$ : CONCLUDING DISCUSSION

$\begin{array}{ll}\text { Navigating Radio Salus’s Frequency } & 104\end{array}$

$\begin{array}{ll}\text { Afterword } & 119\end{array}$

Appendix A - Radio Salus recruitment written exam 121

$\begin{array}{ll}\text { Appendix B - Radio Salus program schedule } & 127\end{array}$

$\begin{array}{lr}\text { Appendix C - Radio Salus new stories } & 128\end{array}$

Appendix D - 2009 EJC / Radio Salus curriculum design 135

$\begin{array}{ll}\text { Works Cited } & 140\end{array}$ 


\section{PREFACE}

For most bitten by the community radio bug, your heart is always with your first station. My passion for radio was ignited in the attic studios and dusty offices of CHMA 106.9 FM, a low power campus-based community station in Sackville, New Brunswick. As any community radio devotee knows, over the years of hanging around and rifling through the vinyl stacks, you learn how a station runs and you experience, most often through trial by fire, how to make things work. An advertising director fixes busted needles on turntables and teaches digital editing. The bluegrass program is produced by a punk rocker that also reads news. The station manager teaches interviewing techniques and flips burgers at a fund-raiser barbeque. This kind of cross-platform flexibility and skill sharing is part of what builds a strong sense of community within the station. My first paid job at CHMA came about in the summer of 1999 when the station, having received a government grant, hired me as a local reporter. I would be hosting and producing a 30-minute community-focused current affairs program each morning. My affable station manager gave me a hand-held cassette recorder with an internal microphone. The training, however, was basic: "Go forth and talk to people". 
I admired the spirit of pounding the pavement and getting off campus and into the community. Yet, I lacked any real sense of the responsibility a reporter has, and of the relationship between one who holds the microphone and one who tells their story. It's embarrassing to admit, but I knew nothing about balanced reporting, interviewing or, even at the most basic level, the mechanics of telling a good story.

A few years later, I found myself in the position of station manager. Between 2001-2003, I was the full-time staff member for a wonderful menagerie of students and Sackvillians. Throughout the course of learning how to coordinate the activities of a volunteer-based radio station, it struck me that what we needed most of all was basic training in radio production and journalism skills.

When I arrived at Carleton University in the Fall of 2005, I came as a "community radio person." Three years later, I'm still a devotee, but armed with new perspective about the intersection of local media and journalism. It sounds trite, but if one thing is certain - context is everything.

Through the Rwanda Initiative, I was introduced to Radio Salus, Rwanda's first community radio station. When I approached Allan Thompson about visiting the station 
and basing my thesis on an examination of how effective Salus has been in training student journalists, he gave me the green light and wisely reminded me to not try and reinvent the wheel.

On the bus ride between Kigali and Butare in November 2007, Radio Salus was blasted through the speaker. In the stores and in the streets, Salus was obviously the favourite radio station.

Salus staff and student journalists were very welcoming, but it was obvious that they had systems of doing things and that it would be up to me to find my place in the busy station. Like a typical international development worker, I wondered exactly what $I$ could contribute. Of course, I wanted to do something.

After seven weeks of working with Salus reporters, I realized that I was just beginning to understand how the station operates and the kind of impact its programming had on listeners. So, a significant aspect of my study was simply being present at Salus, standing back and observing how staff and Salus reporters did things.

How could I possibly understand why Salus operates the way it does until I understood exactly where and from what history it was coming from? The geo-political history and the 1994 Rwandan genocide are well documented in other books, such as in Gerard Prunier's Rwanda Crisis and in Philip Gourevitch's We wish to inform you 
tomorrow we will be killed with our families. The focus for the purposes of this study, however, is the contextualization of broadcast media in Rwanda. When I returned to Butare in the spring of 2008 , I felt I had a better handle on the context in which Salus staff and reporters were working in. I worked with the Saturday Morning Reports current affairs team and, in the process, was inspired by the thoughtfulness, passion and discipline these first and second year students put into producing a weekly program. My study frames Radio Salus within the broader scope of the community radio movement. While on one hand, Salus seems to be an anomaly in the world of community radio, on the other hand it's evident that Salus has many lessons to share with peers in the international community radio movement.

The result of this thesis, I hope, is an outline of how Radio Salus has developed an innovative paradigm as a training ground for broadcast journalists and as an alternative voice on the airwaves. An understanding of the Salus model offers community radio practitioners around the world insight into just how relevant solid radio journalism skills are in developing strong communities. 


\section{CHAPTER I}

\section{INTRODUCTION}

It's Monday evening. A story meeting for Saturday Morning Reports, the English language current affairs program on Radio Salus, is assembled on the grass outside of the Radio Salus studios in Butare, a university town in southern Rwanda. Six first-year journalism students sit with reporter's notebooks perched on their laps, waiting their turn to pitch stories to a producer -- in this case a Canadian journalism trainer sent through Carleton University School of Journalism and Communication's Rwanda Initiative. Story ideas vary from documentaries about the plight of Butare's street children to the issue of rural exodus to a nation wide HIV/AIDS education campaign. A female reporter suggests a feature interview with the soon-to-be crowned "Ms. Campus" at National University of Rwanda's first beauty pageant.

The very same question is fired back at each reporter after they pitch their story idea. That question, in Kinyarwanda, is none se? Or, in English, so what? The reporter who suggested a story about Ms. Campus takes a deep breath and begins to defend her pitch, explaining reasons why this story is worth being told now. If she can articulate how 
the story goes beyond the obvious surface to enhance understanding and encourage dialogue, and the majority of the SMR team agrees, the shared recorder and microphone are handed over.

It is in this same spirit that my own investigation begins. In November 2008, Radio Salus celebrates its third anniversary as the National University of Rwanda's radio station. Since 2005, Salus has held a unique place in the national media landscape as the country's only educational community broadcaster. Being in a small country, the Salus signal is heard throughout most of the provinces in Rwanda, powered by a transmitter not far from the studios in Butare and a second transmitter in capital city, Kigali. From the base of the Ruhengeri mountains in the north to the Burundi border in the south, Radio Salus has established itself as a mainstay on the FM dial, continuing to hold its own alongside Rwanda's private and public stations.

Yet, in its programming and its organizational structure, Salus challenges the convention of contemporary Rwandan radio. Clearly responding to an absence of independent media both before and after the genocide, Salus offers a unique definition of community radio in a country whose destruction was largely mobilized by radio. For Salus, community is not limited to the Butare region where its studios and the national university are located. Salus's projected community is nation-wide. The station is 
simultaneously attempting to produce national news and a wide variety of current affairs programs while also providing a hands-on training opportunity for journalism students at the National University of Rwanda. In a relatively short time period, Salus has become a trusted and popular source of news and entertainment.

This project investigates exactly how Radio Salus's specific community radio model functions as a credible educational medium for participants while also maintaining journalistic integrity. As I will argue, Radio Salus is what anthropologists Lave and Wenger have called a community of practice -- an informal learning community in which experienced practitioners share their practical expertise with newcomers. Radio Salus aims to provide an alternative voice on the Rwandan airwaves, yet, as I will explain, there are ways in which Radio Salus falls short of an ideal community of practice, particularly in terms of its outreach to members of the broader community. Using the knowledge gained from an examination of some of the strengths and weaknesses of Radio Salus's recruitment and training, this study will offer recommendations concerning the radio station's continued development.

Secondly, lessons learned at Radio Salus provide a framework from which to evaluate this particular community radio station model's applicability in other situations. An obvious concern, of course, is the extent to which the Salus model is a product of a 
post-conflict society, thus most adoptable in countries that are, similarly, rebuilding after massive public trauma. Perhaps, though, Radio Salus's model teaches broader lessons that are applicable to community radio stations operating in a variety of settings. I will suggest that it is, in fact, Radio Salus's focus on journalistic skill development that offers a useful lesson to community-based stations in a range of contexts.

\section{Research Method}

Field research was carried out in Butare, Rwanda, in November and December 2007 and in June and July 2008. As an observer-participant at Radio Salus, I worked directly with student journalists responsible for various aspects of programming, including daily news production and a weekly current affairs program.

A cross-section of Salus staff, students and journalism professors at the National University of Rwanda participated in semi-structured interviews I conducted about their particular role at the radio station and their vision for Radio Salus. A focus of the interview was to allow interviewees the chance to self-diagnose their current level of training for their positions and to state their goals in career development.

While my study is limited by the fact that the majority of the station's daily operations and programming are carried out in Kinyarwanda, Rwanda's mother tongue, 
English is spoken by all study participants. English is also the official language in which courses at the National University of Rwanda's School of Journalism and Communication are conducted. While an analysis of Kinyarwanda based programming is not possible, I have endeavored to make general observations based on the translation of one week of daily newscasts and a more general understanding of the programming structure and schedule.

\section{Thesis Organization}

Drawing on existing literature, chapter two is a survey of broad concepts and generally agreed upon principles of community radio in both the developed and so-called developing world. The evolution of development communication and the dominant trends that have emerged in the 20 th century are discussed.

In chapter three, the role of community radio as a development tool in the African context is reviewed. The next section is a contextualization of radio in Rwanda before, during and after the 1994 genocide. This provides the framework in which Radio Salus emerges as Rwanda's first educational community broadcaster.

Chapter four is a historical outline of Radio Salus in terms of its conception, its objectives, its organizational infrastructure and its programming mandate. This chapter 
draws primarily on my field research, both as a participant-observer and through my interviews with Salus journalists, staff, trainers and professors at the National University of Rwanda School of Journalism and Communication. Ultimately, this chapter is an examination of the training methods Salus employs to meet its stated objectives.

Chapter five is a concluding discussion with some general recommendations for Radio Salus, based on my study of training methods, interviews and my experience as a participant-observer over the course of three and a half months at Radio Salus.

\section{SO WHAT?}

An analysis of the Radio Salus' model has implications for the practice and teaching of community radio internationally. First of all, this thesis documents the emergence of what is arguably the first generation of professionally trained journalists in Rwanda. An important part of their practicum is carried out at Salus, where my study is based. The question of how effective a community radio station is as an educator is at the heart of my examination. The educational model of Salus concerns both the journalists in training as well as the audience engaging with the radio programs.

Secondly, community radio is constantly lauded as a tool for development, particularly in Africa where radio is the most prevalent media. Often these stations fit the 
rural / farm radio model in which local farmers participate in creating radio content.

Since Salus's on-air programmers are composed almost entirely of journalism students, the idea of development is linked to balanced journalism and professionalism rather than public participation.

Finally, for Canadian journalists, community radio practitioners and teachers, Radio Salus is an opportunity to look at how we can contribute to and learn from the experience of alternative radio in Rwanda.

Currently, Carleton University's Rwanda Initiative is instrumental in providing established Canadian journalists to teach at the National University of Rwanda. As journalists and trainers from the developed world, this is an area we need to tread with sensitivity. It goes without saying that it's essential to review whether the program is having a positive, sustainable impact and, perihaps, how it needs to be altered or expanded.

While some general shared principles exist, it's becoming increasingly complicated to make comparisons between modes of community broadcasting in the western world and those of the so-called developing world. Because media needs are so fundamentally different in Rwanda than those in Canada, we need to revise how we teach and evaluate community radio and journalism. 
Beyond training and teaching, what underscores this community radio station investigation is a reflection on the tremendous responsibility of media, particularly in a post-conflict country. While it seems rather idealistic to claim that a community radio station can affect the political climate of a country, history has exposed the power of radio in East Africa. The relationship forged between a community radio station and its listeners should proceed with cautious and self-conscious steps. As a radio station has a role to play in building public trust through journalistic principles, it's equally capable of betraying social trust. 


\section{CHAPTER 2}

\section{COMMUNITY RADIO OVERVIEW}

Our movement encompasses a wide range of practices. In Latin America we speak of popular radio, educational radio, miners' radio or peasants' radio.In Africa, we speak of local rural radio. In Europe of associative radio, free radio, of neighborhood radio and of community radio. In Asia we speak of radio for development and of community radio. In Oceania, of aboriginal radio, public radio and of community radio. All these types of radio reflect a large diversity. The diversity of this participatory radio movement is large and very rich. In this we find our strength. (Delorme in Lewis 1993)

The technology involved in building a small radio station is not impossibly

complicated. With a small antenna, a donated transmitter, an amplifier, a roll of audio

cable and a compact disc player or -- more common in today's studio - a computer loaded with Mp3 files, an individual with a basic aptitude for electronics can assemble a radio station and subsequently train others to operate studio equipment.

Ranging from detailed technical guides to anarchist-styled Do It Yourself (DIY)

manifestos, plenty of resources exist on-line and in libraries to walk an organization (or an individual) through the construction of a radio station, from the ground up.

National Campus/Community Radio Association in Canada (NCRA) and

Prometheus Radio Project in the United States are non-profit organizations that directly support community radio development. The NCRA networks some 140-member 
community radio stations across Canada and encourages mentorship between established radio staff and inexperienced community radio applicants. For Prometheus, a big part of the organization's ethos is demystifying the technological side of the medium by teaching technical skills to new community station staff. Both organizations are united in an overarching objective encouraging community-based broadcasting operations. Community radio has evolved as a grassroots-based media that emphasizes teaching skills at all levels of the station's operations. It's not uncommon for radio stations to have an informal apprenticeship system in place to offer training in everything from fixing busted turntables to putting together a daily newscast.

Yet, as the history of the sector in North America has unfolded, community radio has had an ongoing struggle to simply stay on the air. As a typically volunteer-rich but financially-poor operation, the few resources a station has are often thinly stetched in an effort to perpetually fundraise to pay a few overworked staff members and to replace desperately needed equipment (Zaltz, interview, 2007).

An equally draining focus of the sector in North America is the need to consistently lobby government legislators for recognition and protection. Low power community broadcasters are often competing against private, commercial broadcasters to protect their right to a frequency on an increasingly over-crowed FM band, particularly in 
urban areas. In the past twenty-five years, the NCRA has intervened in hundreds of Canadian Radio-Television Communications Commission (CRTC) hearings to plead the importance of low-powered community broadcasting when confronted by a newly licensed commercial mega-watt transmitter threatening to bump every station within a thousand kilometers off the airwaves (ibid).

Despite being a resource-poor sector ill equipped to compete against commercial radio, the relevance of local, community-centered media in a democratic society has been a reoccurring theme in contemporary media consolidation debates.

This literature review begins with an overview of the struggle for community radio in the United States and Canada, with a particular focus on the low-power radio movement. This broad overview of low-power community radio in North America attempts to provide a bird's-eye view of the context in which community radio gained a profile in the western world. The North American community radio model provided the framework by which African models emerged.

In North America, community radio tends to be primarily categorized as a communication alternative. Whereas mainstream media's coverage of events is general, community media represents "the wide range of activities, values and aspirations present in the community which are not given expression in the daily press" (Janowitz in Lewis 
26). Through the individual programs presented by community members, an overall community identity is articulated. In this sense, access to a radio station is conceived as a tool of individual and collective empowerment, enabling self-representation through media.

In the developing world, however, community radio is primarily conceived of as a development medium, at least by the western world. In Africa, as will be discussed, community radio was first employed as an ideal tool with which information could be disseminated from so-called experts to people living in rural areas presumed to be underdeveloped. Since the 1990s, however, community radio has proven itself a viable alternative to private and national broadcasters in some African countries.

The issues regarding community radio's role as a development medium are addressed in the following section in which leading theories in the field of development communication are examined.

Finally, Radio Salus in Rwanda, the central case study of this thesis, is introduced as a unique community radio archetype. 


\section{The Battle for Low Power Radio In The United States}

In the United States, there has been a concentrated mobilization around the microbroadcasting, or low power radio movement. The ethos and struggle of community radio has been portrayed, and perhaps romanticized, in mainstream entertainment. The 1990 film Pump Up The Volume featured Christian Slater as a misunderstood teenager broadcasting messages of existential angst, while also challenging his fellow high school students: "Do you ever get the feeling that everything in America is completely fucked up?" His bedroom radio station, an unlicensed pirate station in which he is the sole deejay under the pseudonym Hard Harry, is the setting for nighttime clandestine broadcasts.

When the federal communications regulatory body, the Federal Communications Commission (FCC), launches an investigation of the pirate signal, the Slater character dismantles his station and mounts an antenna on his mother's jeep, creating a mobile transmitter. Broadcasting his final message to a crowd of gathered teenagers (while the authorities stand by waiting), he encourages students to decide their own future and realize the world belongs to them. As the police arrest Slater and his partner-in-crime girlfriend, he quips the familiar Hard Harry line: "Talk hard." As the film ends, other students begin their own independent stations, which are heard broadcasting across town. 
Illicit, low power broadcasting gained a profile in popular culture in Pump Up The

Volume. Yet, the film also alludes to tensions between micro-broadcasting advocates in the United States and the FCC.

Pirate radio in the United States, particularly in the 1990 s, stands as a subversive gesture against public policy. In 1978, the FCC revamped its regulations for broadcasting licences. By dropping 'Class D' from their eligible licensee categories, it made legal low power broadcasting financially insurmountable for many potential community groups. Since then, lobbying the FCC for low power, community-based frequencies, or low power FM (LPFM) licenses has been a major priority for community radio advocacy organizations (Prometheus Radio, 2007).

The policy decision that left out low power radio was based on the belief that LPFM signals, however small, would interfere with bigger broadcasters, including larger public and non-profit stations. An alliance between National Public Radio (NPR) and the National Federation of Community Broadcasters (NFCB) argued that available frequencies on the FM band were disappearing. As Charles Fairchild notes in his essay "The Canadian Alternative: A brief history of unlicensed and low power radio," both organizations called for a "professionalization" of public and community radio, convincing the FCC to limit the number of low-watt broadcasters in favor of larger 
broadcasting operations (Fairchild,1998:54). The FCC placed restrictions on existing low power frequencies and shut the door for any new LPFM licence applications.

Ironically, the outcome of FCC's LPFM policy changes was the creation of the micro-power radio movement. There is no lack of information and sources about the issue of LPFM, a situation unique to the United States, and Stephen Dunifer of Free Radio Berkeley, and those behind the Prometheus Radio Project are at the vanguard of the movement.

Free Radio Berkeley is both a community radio station in Berkeley, California and an organization dedicated to providing practical resources for micro broadcasters. Electrical engineer Stephen Dunifer launched a pirate radio station in 1993, claiming he was disgusted with the unbalanced reporting of the Gulf War. After a few years of clandestine transmissions, the FCC picked up his signal and fined Dunifer for broadcasting illegally.

The court case that ensued after Dunifer refused to pay the fine was a turning point in the low power radio history of United States. The National Lawyers Guild, who represented Dunifer, argued that "micro-radio is the leaflet of the nineties" and that forbidding it was essentially an issue of censorship (Prometheus Radio, 2000). 
In November 1997, Judge Claudia Wilken prohibited the FCC from collecting $\$ 20,000$ in fines from Dunifer pending review of the constitutionality of current FCC licensing practices.

Dunifer's ongoing work with Radio Free Berkeley includes an on-line archive of technical documents and resources for broadcasters. The organization regularly travels to communities across the United States to hold transmitter-building workshops.

In the introduction to his 1998 book Seizing The Airwaves: A Free Radio

Handbook, Dunifer encourages civil disobedience with the objective of reforming the regulatory framework surrounding LPFM.

And now, good citizen, the next chapter is up to you. How will you write it? Will you take part in this movement to democratize not only the airwaves but all means of communication? It does not take much in the way of resources to put a community voice on the air. In fact, the cost can be kept to $\$ 1000$ or less. Are you satisfied with format and formula radio? Does the media reflect the diversity of your community? Do you believe in the First Amendment and the right to tell the truth? Why not consider putting a micropower FM radio station on the air in your community? (Dunifer 4-5)

Dunifer's commitment to micro-power broadcasting paved the long road for reform currently taking place within the U.S. congress and in FCC's evolving policy. Prometheus Radio, a non-profit community radio advocacy organization founded by activists in 1998, has made a consistent and concerted effort to lobby Congress for the 
expansion and protection of LPFM signals, particularly as a means of fighting media consolidation.

From their church basement headquarters in west Philadelphia, Pennsylvania, Prometheus offers LPFM applicants advice on filing license applications and navigating the FCC bureaucracy.

In 2000, the FCC opened a one-time window to accept low power radio applicants. This was largely a result of Prometheus's organized protests and lobbying in Washington, D.C. The FCC was flooded with 3,200 applications from community groups, church groups and civil rights organizations. The commission granted approximately 800 licences, without making commitments for future opportunities for LPFM applications (Prometheus Radio, 2000).

In 2007, the United States Senate Commeree Committee voted to report Bill 1675, the Local Community Radio Act of 2007, to the full Senate. If passed, the bill would open the gates for thousands of new low power radio stations. Prometheus Radio will go down in the annals of low power radio history as having played a major role in challenging and reforming LPFM policy in the United States.

Another component of Prometheus's work, at least since the limited granting of LPFM licences in 2000, has been radio station barn raisings. Prometheus has partnered 
with various successful LPFM recipients to facilitate three-day conferences in which a new radio station is completely built, from raising the antenna to wiring the on-air switch, by local and visiting volunteers. Fashioned after traditional barn raisings when an entire community came together to construct a large building, radio barn raisings are collaborative and highly spirited events emphasizing participation on all levels. Later discussion on the various models of community radio will refer to a Prometheus radio barn-raising in Immokalee, Florida, in December 2004 and the impact the station has had on the community and participants (Prometheus Radio, 2007).

Although on one level, Prometheus is very much involved in both the political challenge of low power radio as well as the nuts and bolts of physically building a radio station, the organization's philosophy is based on making radio representative of the communities it inhabits. Founder Pete Tridish, the organization's main technical director and adviser, sees himself as a crusader with a social mission: "A town without a community radio station is like a town without a public library or public schools or public parks, where people from all walks of life can come together" (Gurwitt in Prometheus Radio, 2000).

This brief overview of the political climate for low power radio in the United States simply underlines the passion and determination of community radio enthusiasts. 
Where provisions for community radio stations were not legislated, local citizens have banded together, formed networks and found a means to broadcast or have lobbied congress to support media reform.

\section{The Canadian Low Power Radio Experience}

In Canada, the Canadian Radio-television and Telecommunications Commission (CRTC) regulate the airwaves. When Radio Free Berkeley's Stephen Dunifer was on trial, he argued that low power broadcasting in Canada could serve as an ideal model for licensing reform in the United States (Dunifer 52).

Early Canadian public radio institutionalized, to some extent, a few of the principles guiding the low power community radio movement. The National Farm Radio Forum (NFRF) is the most obvious example of a regular regional broadcast in which local listeners were invited to participate, addressing program content through discussion groups. Between 1942 and 1965, the Canadian Broadcasting Corporation (CBC) teamed up with the Canadian Association for Adult Education (CAAE), the Canadian Federation of Agriculture (CFA) to produce a weekly radio program about agricultural issues. Across Quebec, Ontario, the Prairies, British Columbia and the Maritime provinces, 
listeners would first read an information booklet provided by the NFRF on that week's topic, then listen to the show and afterwards, participate in a discussion group (a forum) inspired by the program topic (Sim, 1986).

The NFRF was entrenched in affecting policy change through listener participation and the "Read. Listen. Discuss. Act" philosophy (ibid). Forums were encouraged to report the results of their discussion to the National Farm Radio office, which would then be tabulated and included at the beginning of the ensuing broadcast. The success of the program eventually declined as did agriculture-based communities across Canada, R. Sim, one of the movement's founders, says educational aspect of the programs led citizens to engage in other forms of "political action and community development" and inspired a "generation of leaders who made their ideas known in parliaments, in farm organizations and in international agriculture" (ibid).

Certainly, the Canadian farm radio movement provided a model for other agriculture-based communities with access to a radio station. UNESCO found the NFRF model particularly adaptable to African countries and the forum was introduced to Ghana in the late sixties and early seventies (McKay 43).

The origin of low power community radio in Canada also has roots within northern aboriginal and First Nations communities. Isolated communities such as Pond 
Inlet, Nunavut (at the time, Pond Inlet was part of Northwest Territories) first experimented with small two-way radio equipment as early as 1964 (Fairchild 49). The first attempts utilized scavenged equipment from Royal Canadian Mounted Police (RCMP) operations or from government offices, such as the Department of Indian Affairs (DIA).

With so-called trail radio equipment brought in by government, residents found they could "communicate with those out on hunts or on the trap-lines in order to mitigate the seriousness of possible emergencies" (ibid). When residents of Pond Inlet realized they could broadcast news, public information and music, "they scrounged record players, rebuilt the ham radio equipment to operate with 10 watts of power on the amateur band and started their own station" (Fairchild ibid). According to Liora Salter, author of "Community Radio in Canada", the Pond Inlet station broadcast in this manner for a few years until their signal was picked up by two pilots flying into Montreal. When the CRTC subsequently was made aware of Pond Inlet's broadcasting, the regulatory agency requested the community comply with existing broadcasting regulations.

The Company of Young Canadians, a government-funded group of university students mandated to work for social change, also has a notable place in the history of low-power broadcasting in Canada. In 1969, they collaborated with a group of Ojibway 
who lived along the Longlac region of Ontario in a mobile radio experiment known as Radio Kenomadiwin. They outfitted a van with radio equipment and their objective was to teach basic radio production skills to aboriginal participants. According to Liora Salter, Radio Kenomadiwin also had "the express purpose of documenting a series of scandals in government administration of native affairs" (Fairchild 49).

Although Radio Kenomadiwin, a licensed mobile broadcaster, intended to "include programming that was local in origin and available in the native language" (50), the continuity and impact of its operation is uncertain. On the website of For the Friends of Canadian Broadcasting, an independent non-profit organization that acts as a public radio watch dog, a blogger with the initials 'EP' writes that Kenomadiwin broadcast to a number of reserves for several years and received technical support from CBC Thunder Bay (then called CBQ).

As Fairchild notes, however, the lasting impact of the Kenomadiwin experiment was that it set an important precedent for the potential of community radio, influencing practical and policy guidelines for future community radio undertakings, and inspiring the Northern Broadcasting Policy. ${ }^{1}$

\footnotetext{
'While the CRTC acknowledges the existence of radio in the north in the 1960s, it claims that development remained slow until the implementation of the Northern Broadcasting Policy in 1983. This policy was based on principles of access to distribution
} 
In the contemporary north, community radio continues to play a role in connecting isolated communities as well as promoting indigenous language, culture, tradition and local news. In "Indigenous Radio in Canada", Valerie Alia notes the pervasiveness of volunteer-run community radio stations. CHON-FM, the indigenous radio station based in Whitehorse and operated by Northern Native Broadcasting Yukon (an aboriginal communications society), is heard in "offices, homes, school and out on the land". It broadcasts in seven aboriginal languages and in English throughout the territory and into Alaska. While this station has a much larger broadcasting range than the low-power projects discussed above, as well as full-time staff and a board of directors, CHON-FM relied on volunteer reporters in communities across the Yukon to telephone local newscasts for broadcast until recently (Alia 78 and Adamson, 2008 correspondence).

Aboriginal broadcast networks such as Northern Native Broadcasting Yukon and countless "pirate" and "bush" radio stations operating solely on volunteer power in the north, represent a diversity of radio experiences in Canada's north that have, arguably, systems (such as CBC) to encourage protection of language and culture. In 1991, this right was enshrined in the Canadian broadcasting act (Public Notice CRTC 1990-89). 
been reflected in CRTC policy revisions over the last two decades. The tie that binds aboriginal programming objectives to the national policy that evolved is the need for programs that "foster the development of aboriginal cultures, and where possible, the preservation of ancestral languages" (Public Notice CRTC 1990-89). An equally important aspect of the Native Broadcasting Policy is that the commission "encourages the participation by aboriginal people in all aspects of the broadcasting system" (ibid). From production to programming, where geographically possible, the emphasis is on public access and participation.

The CRTC's regulatory policies were drafted, in part, as a result of political pressure applied by grassroots aboriginal groups, francophones and student radio groups (Fairchild 55). The Broadcasting Act (1991) is the umbrella policy for radio transmission in Canada that includes provisions for low power radio ( 50 watts and below), larger community radio broadcasters ( 50 watts and above) and aboriginal stations. As in the United States, the commission differentiates between campus (connected to college or university and generally partially subsidized by students or school) and community (autonomous non-profit organizations funded by listeners, advertisers or fundraising events). Interestingly, in the revised campus policy (2000), the CRTC changed the name of campus radio to campus-based community to denote the important role campus-based 
radio stations have within the communities they broadcast in. Furthermore, the policy states that training in radio production should be accessible to members of the community at large as well as to the student body.

CHMA-FM, a 50-watt campus-based community radio station in Sackville, New Brunswick is a non-profit organization broadcasting from the campus of Mount Allison University. Although it was founded as a campus radio station, its members chose to incorporate the station as an autonomous organization, Attic Broadcasting Inc. In a referendum, the student body voted in favor of providing a levy to contribute to CHMA's operational costs, and the station also has an annual community membership drive and holds regular fundraising. The programming consists of music and spoken word content produced by both students and members of the Sackville community. The station has one full-time staff member and several part-time staff, typically students. ${ }^{2}$

In Canada, about 140 campus-based community radio models exist (this includes English and French language stations), many of which are staffed by between one and three full-time employees and subsisting on a mixture of student levies, advertising, fundraising revenues and community memberships (Kaestner, email correspondence, 2008).

${ }^{2}$ Between 2001 and 2003, the author was station manager at CHMA Radio. 
A strictly community radio station relies on generating advertising, donations and

memberships from volunteers and listeners to survive. The CRTC defines a community

radio station as follows:

A community radio station is owned and controlled by a not-for-profit organization, the structure of which provides for membership, management, operation and programming primarily by members of the community at large. Programming should reflect the diversity of the market that the station is licensed to serve. (CRTC 2000-12)

Vancouver Co-op Radio is the quintessential example of a long-standing community

radio station in Canada. It was founded in 1974 in east side Vancouver by 231 interested shareholders. Besides public affairs and music, the programming schedule includes shows in Farsi, Korean, Spanish and other languages representative of Vancouver's cultural diversity.

Community-based campus and community radio policies are 'reactive' in that the CRTC does not monitor stations' daily activities, but will respond to specific complaints or criticism that a station is not living up to its Promise of Performance, a detailed programming agreement based on the organization's programming objectives and mission statement.

Unlike the United States, the Canadian government has made low power radio legal, legitimizing its presence in many urban and rural settings across the country. One 
significant aspect some scholars such as Fairchild have neglected to point out about Canadian low power policy, however, is that radio stations with 50 watts or less of radiated power are not protected from signal interference of encroaching bigger stations.

For instance, in 2007, both private and public stations in nearby Kingston came close to overpowering Amherst Island Community Radio's (AICR) low power signal. AICR's only solution was to apply for a protected 250 watt (class B) community radio licence, requiring a costly transmitter replacement. Amherst Island Community Radio was awarded the licence in December 2007 (CRTC 2007-376) and is now safe from signal interference.

\section{Further Defining Community Radio}

Because community is such a nebulous concept, community radio defies simple definition. In Radical Media, John Downing notes that community implies "a seamless social tissue that is local and therefore healthy" (38). For Downing, the assumptions of harmony, cooperation and inclusion that are wrapped up in notions of community are not necessarily accurate or particularly indicative of all forms of community media. Peter Lewis also acknowledges the presuppositions and inevitable baggage the word carries, 
but settles on using community radio, the term most commonly used by practitioners, to describe a broad range of locus-specific media experiences (Lewis 12).

In 1916, John Dewey conjectured that communication is an essential part of articulating community: "Men (sic) live in a community in virtue of the things which they have in common; and communication is the way in which they come to possess things in common" (Dewey 5). For Dewey, it's not simply physical proximity that constitutes community, but rather the ability to share information about "what the other is about" (ibid) and their progress.

Perhaps, then, a more useful conceptualization of community radio can be had in its potential power of expressing a sense of place through its citizens. While it's generally characterized by local participation, its identity remains shaped by the people directly involved with the station's operations: staff members, board members and volunteers. And, the station itself constitutes its own distinct community with its own station-specific culture and traditions.

At some stations, the ethos of community radio places process over product: "It is above all a process, not a technology, not merely a means, because the people are part of that means, and so is the message and so is the audience" (Arnold in Fraser \& RestrepoEstrado, 2001). As Alfonso Gumucio-Dagron and Thomas Tufte note in their 
introductory remarks in Communication for Social Change, an extensive development communication anthology, technological tools are the least important aspect of an alternative media undertaking. They write: "It is not simply a matter of owning the tools, e.g., a radio station, a newspaper or a television channel, but also a question of, or appropriating, the communication process, including content design, management and decision making" (Gumucio-Dagron \& Tufte xix). In this vein, for micro-radio practitioners in the Unites States, the battle takes place at the policy level. As Prometheus Radio states on its website, "the barriers to setting up a radio station have always been legal and political, rather than technical."

Without settling on a decisive definition, the World Association of Community Broadcasters (AMARC) lists the multitude of definitions its members have proposed to represent community radio. Linking this compilation of definitions are underlying principles of local participation and ownership of the process and vision of the station (AMARC, 2003). Equally important is offering airtime to previously marginalized or underrepresented peoples in order to encourage development or social change.

Community radio [is] a type of radio made to serve people; radio that encourages expression and participation and that values local culture. Its purpose is to give a voice to those without voices (Girard, 1992; ix) 
According to Fraser and Restrepo-Estrada (2002) the principal functions of

community radio are:

- To reflect and promote local identity, character and culture by focusing principally on local content;

- To create a diversity of voices and opinions on the air through its openness to participation from all sectors;

- To encourage open dialogue and democratic process by providing an independent platform for interactive discussion about matters and decisions of importance to the community;

- To promote social change and development;

- To promote good governance and civil society by playing a community watchdog role that makes local authorities and politicians more conscious of their public responsibilities;

- Sharing of information and innovation;

- Giving a voice to the voiceless, especially to women and young people in some societies;

- Providing a social service as a replacement for the telephone. ${ }^{3}$

\footnotetext{
${ }^{3}$ Particularly before the advent of cellular phones, radio has been used as a communication device to link people in remote or isolated communities.
} 


\section{Branches of Development Communication}

To understand the reasons why community radio has materialized as a vital force in democratic media, it's worthwhile to examine broader communications theory. The field of development communication, or communication for development, emerged since the Second World War. From the two dominant branches of development communication, modernization and participatory development, it's evident that community radio has risen and evolved in response to political and social trends. Participatory communication is a more recent branch of communication development theory in which participation in a media project is emphasized.

\section{The Modernization Paradigm}

The concept of development, in general, is the metaphor of growth, as articulated in the works of $19^{\text {th }}$ century philosophers such as Condorcet, Comte, Durkheim, Saint Simon, Spencer, and Karl Marx (Servaes 19). The modernization paradigm, of which diffusion development derives, was the popular model from around 1945 until 1965 (ibid). Growth, in this conceptualization, is identified within a Western framework of progress in which the gaps between rich and poor, modern and traditional are bridged. 
Servaes posits that economic indexes, such as income, savings and investment, are at the root of the modernization paradigm, although "attitude change, level of education, mass media, and institutional reforms were introduced" (Servaes 20). Consequently, modernization emphasizes that the poorest nations must adopt the same technological advances as developed nations in lieu of traditional practices in order to achieve greater economic and social advancement. Diffusion theory is the concept of sharing innovations from developed nations, such as Canada, the United States and European countries, with less-advanced rural countries in Asia, Africa and Latin America (ibid).

In the field of communication development, the writing of Wilbur Schramm (1954) and Daniel Lerner (1958) mark the beginning of modernization theory. Both theorists believed that the poorest nations could benefit by exposure to the "modernized" Western society. In The Passing of Traditional Society (1958), Luner argued that by exposure to Western values, people in traditional societies would become civilized members of society and develop "empathy."

The idea of empathy, writes Lerner is "the capacity to see oneself in the other fellow's situation... which is an indispensable skill for people moving out of traditional settings" (Lerner 50). Central to this concept is the individual's ability to develop the necessary psychological skills for making the transition from a traditional to a modern 
society. As Servaes articulates: "Empathic persons had a higher degree of mobility, meaning a higher capacity for change, being future oriented and rational, more than socalled traditional people" (Servaes 1995). Lerner saw media as a kind of a vaccination needle having the potential to insert traditional societies with a sensibility to modernize, or in another word, to westernize.

Schramm, too, saw traditional customs and practices in the so-called Third World as possible obstacles towards development. The transition towards development could be profoundly influenced by mass media. He writes, "in the service of national development, the mass media are agents of social change" (Schramm 31). Clearly, however, those progressive ideals, which could be diffused through media, are based on Western standards:

By showing modern equipment and life in economically well-developed societies, by disseminating news of development from far away, by carrying political, economic, social and cultural reports from elsewhere in the country and the world, the media can create an intellectual climate which stimulates people to take another look at their own current practices and future perspectives. (Schramm 31)

Diffusion theory, in practical terms, is when television and radio are employed to transfer information from a knowledge centre to those perceived to be uneducated or under-developed. The diffusion of innovation model, introduced by Everett Rogers 
(Rogers 1962), has been widely used in the health and agriculture sectors (GumucioDagron, xvii). This model uses a top-down, one-way flow of information in which media are used to transfer information from "expert" researchers to a target group of farmers (McKay 20-1). According to Rogers, development communication must involve a "process by which an idea is transferred from a source to a receiver with the intent to change his [sic] behaviour. Usually the source wants to alter the receiver's knowledge of some idea, create or change his attitude towards the idea or persuade him to adopt the idea as part of his regular behavior" (Rogers in Waisbord 4).

In 1962, the United Nations Educational, Scientific and Cultural Organization (UNESCO), a United Nations agency, began urging every country, particularly African countries, to include communication development plans in their national development agendas (Ojo 2004). This was based on a series of meetings that brought together media experts, academics and country representatives. In December 1962, UNESCO passed a resolution expressing concern that more than 70 per cent of the world lacks adequate information facilities and are effectively denied the right to information. The resolution went on to say, "Information media have an important role to play in education and in economic and social progress generally" (UNESCO 1964 as cited in Ojo 2004). Schramm actually worked for UNESCO during this period, known as UNESCO's 
program of concrete action. His role was to develop practical methods as well as offering scholarly analysis on the application of media in developing countries. Both Schramm and Lerner held the belief that "greater accessibility, exposure, and the use of mass media correlated positively with literacy, economic well-being and political participation" (Huesca in Ojo).

\section{Dependency Theory}

In the late sixties, alternatives began to emerge to challenge the dominant paradigm of modernization by diffusion. On the ground, the reality for many Third World countries was an ever-widening gap between rich and poor, and between urban and rural citizens. These same countries were also becoming increasingly dependent on western machinery, technology and capital (McKay 21). Waisbord notes that at this point, development communication split into two broad approaches: "one that revised but largely continued the premises and goals of modernization and diffusion theories, and another that has championed a participatory view of communication in contrast to information - and behavior-centered theories" (Waisbord 15). 
In Latin America, dependency theorists, or dependistas, argued that development problems in the Third World were a consequence of capitalistic expansion (Waisbord 17). The central argument of dependency theory is that development obstacles are created by external sources, as opposed to being internal problems. By exploiting underdeveloped countries, dependistas argue, rich countries have prospered (Servaes 1999). Rather than lacking information or being ignorant, poor countries were not developing because of political reasons - namely, the global expansion of western capitalism. Because modernization theory overlooked the role media ownership plays in development, dependency theorists called for a revised approach to communication development (Waisbord and McKay).

\section{Participatory Communication}

The idea that active participation in a communication project should form an essential aspect of basic democratic organization is a component of participatory communication. Access, participation, and self-management are central to participatory media projects (Servaes, 1995). Tracing the term communication, Gumucio-Dagron 
claims English speakers have misinterpreted the word to mean information rather than participation:

Etymologically the Latin communio relates to participation and sharing. Modern languages have given different meanings to the word communication, it is often considered synonymous with information. There is confusion, mostly by English speakers, between communication - the act or process of communicating, and communications with an " $\mathrm{s}$ " - the means of $s$ sending messages, orders, etc. (Gumucio-Dagron, 2001: 33)

Perhaps, Bertolt Brecht, a German playwright and poet, was ahead of his time when he proposed a kind of participatory communication, albeit an abstract type, in "The Radio As An Apparatus of Communication " in 1927: that radio could be a communicator, capable of hearing as well as speaking, rather than a simple distributor of information.

He writes: "The radio would be the finest possible communication apparatus in public life, a vast network of pipes. That is to say, it would be if it knew how to receive as well as to transmit, how to let the listener speak as well as hear, how to bring him into a relationship instead of isolating him" (Brecht 1927). Although Brecht was particularly concerned with radio's potential as an artistic animator, his essay provides a compelling call for participatory communication, insisting that audience can be teachers as well as pupils. 
There are two widely recognized dominant approaches to participatory communication. The first comes from Paolo Freire, a Brazilian educator, who stressed dialogue and participation as the path to finding solutions to local development problems. The second approach emerged from the UNESCO debate of the 1970s that emphasized the institution, such as a radio station, as the focal point in which access and participation can gradually evolve (Servaes 162). Before discussing how varied approaches to participatory communication have become, it is worth noting the points of common ground.

In the late 1960s and early 1970s, Paolo Freire was organizing South American peasant groups and developing innovative ways to teach literacy skills. An understanding of communicative actions, although not necessarily media, was central to his ideas (Waisbord 19 and Servaes 161). In his seminal work Fedagogy of the Oppressed, he argues that transformation takes place only when it is based on dialogue, a participatory exchange, rather than diffusion models in which, for instance, farmers are persuaded to adopt Western innovations. (Waisbord 18). Freire's pedagogy of liberation aims to engage participants in a process, facilitated by an animator, in which they would learn to identify their own reality and subsequently figure out how they could change it. He writes that education is not "bits of information to be deposited in students" (Freire 1970). 
Freire proposed a term, conscientization, from the Portugese word conscientização, meaning "learning to perceive social, political, and economic contradictions, and to take action against the oppressive elements of reality" (Freire 17). Scholars and practitioners in the participatory communication field credit Freire's books as having contributed a theoretical framework for an alternative development communication. Gumucio-Dagron acknowledges Freire when he writes: "The concept of participatory development has led to a greater level of understanding of the role of communication for development" (Gumucio-Dagron, 2001: 9). Although Freire does not directly address mass media, he rejects the diffusion paradigm made popular by Western development agencies in favour of finding solutions at the grassroots level.

UNESCO hashed out a discourse for participatory communication at a 1977 meeting in Belgrade, Yugoslavia. According to Servaes, the final report outlines the significance of self-management, access and participation, as Freire had done. The difference for UNESCO's concept, however, is that while some degree of access by the general public should be assumed, self-management is a gradual progression, assumedly evolving from interaction with the involved institution. While participation, in this sense, involves the public in both the production and management process, it can also be no more than representation and consultation (Servaes 162). Freire's theory did not make 
compromises and demanded complete and equal access and participation from all members of a community.

Participatory communication takes on many forms and largely depends on the community itself and its collectively defined priorities for its communication media. Despite the general acceptance of the ideas posited by Freire and UNESCO, there is an incredible diversity of media projects defining themselves as participatory. One element all these projects have in common, of course, is working at the community level rather than taking orders from a decentralized agency or a national bureau.

In Canada, the National Film Board's Fogo Island Process is a concrete example of a project informed by participatory communication principles. In 1967, community members living in economically depressed, isolated Newfoundland outports produced films discussing problems in their town, as well as possible solutions. While the Fogo Island Process opened up a much-needed deliberation among community members, films were also broadcast on national television. The produced material also served to communicate Fogo Island's perspectives to outsiders. (Waisbord 20 and Howley 52). Rural radio forums and radio listening clubs, which will be discussed in more detail in chapter three, also follow participatory communication principles. The general idea with 
participatory projects is that through some aspect of taking part in producing a product, participants can work out solutions to their problems.

Whereas modernization and diffusion focused on development through information or persuasion to adopt new social or economic practices, participatory theory encourages participation, stimulating critical thinking and stressing process instead of specific outcomes (Waisbord 20). Indigenous knowledge and the role of people in naming their development aspirations are central to participatory communication (Waisbord 21). Horizontal, participative communication models are favoured over oneway, top-down approaches.

\section{Participatory Communication For Social Change}

A discourse revolving around participatory communication's potential as an agent to inspire social change has evolved in the last decade. Perhaps a movement away from the baggage of the term development, participatory communication for social change is viewed as an integral, multidimensional, and dialectic process that differs depending on the cultural context (Servaes 1999). Since 1997, the Rockefeller Foundation has promoted scholarly work and discussion under the umbrella of the Communication For 
Social Change Consortium (McKay 24). Dialogue is at the root of this communication process, encouraging "people themselves to define who they are, what they want and need, and how they will work together to improve their lives" (Gumucio-Dagron, xiv).

Although approaches are diverse, Gumucio-Dagron claims that the main elements characterizing participatory communication for social change are "related to its capacity to involve the human subjects of social change in the process of communicating" (Gumucio-Dagron, 2001; 34). To distinguish participatory communication for social change from other development strategies, particularly diffusion-modelled approaches, he offers the following characteristics:

- Horizontal vs. Vertical: People as dynamic actors, actively participating in the process of social change and in control of the communication tools and contents, rather than people perceived as passive receivers of information

- Process vs. Campaign: People taking control over their future through process of dialogue and democratic participation in planning communication activities

- Long-term vs. Short-term: Communication and development in general perceived as a long-term process which needs time to be appropriated by the people

- Collective vs. Individual: Urban or rural communities acting collectively in the interest of the majority, preventing the risk of giving power to a few

- With vs. For: Researching, designing and disseminating messages encouraging participation 
- Specific vs. Massive: The communication process adapted to each community or social group in terms of content, language, culture and media, rather than the tendency to use the same techniques in diverse cultural settings

- People's needs vs. Donor's musts: Community-based dialogue and communication tools can help identify and define real needs and felt needs

- Ownership vs. Access: A communication process that is owned by the people to provide equal opportunities to the community

- Consciousness vs. Persuasion: A process of raising consciousness and deep understanding about social reality, problems and solutions (Gumucio-Dagron, 34-5)

Gumucio-Dagron maintains that when people have an opportunity to be active participants in communication at the community level, they become empowered. When decision-making is put back into their own hands, democratic processes are strengthened (Gumucio-Dagron 34).

Rad Conciencia in Immokalee, Florida, is a concrete example of a radio station that subscribes to principles of participatory communication for social change. ${ }^{4}$ This particular radio station is based in a town in which more than half the population are

\footnotetext{
${ }^{4}$ In December 2003, I worked with Prometheus Radio to help train volunteers while Radio Conciencia was being built. In February 2008 I paid another visit to Immokalee to see how the station had held up. The Coalition For Immokalee Workers is a well-known American social activist organization that led the successful Boycott Taco Bell campaign. While the Coalition has a handful of paid staff, funded through various foundations, Radio Conciencia does not have any staff of its own and relies on volunteers.
} 
migrant farm-workers from Mexico, Guatemala and Haiti. They live in Immokalee for a temporary period, often just a few months, to pick tomatoes before moving onto another state, Georgia or Florida, to pick peaches, oranges or whatever the harvest might be. While in Immokalee, migrant workers find renting expensive and live in overcrowded mobile homes with other migrants. In the tomato fields, some migrants have claimed they face inhumane working conditions and poor wages.

The Coalition for Immokalee Workers, a labour rights organization, sought to create a community radio station to enhance its ability to spread information among workers about unjust farms, while also informing workers about their rights. Ultimately, the Coalition hoped the radio station would build support for their movement and campaign to demand multi-national corporations pay higher prices for tomatoes, thus increasing the per tomato price paid to pickers. The radio station would also be a central entertainment source for the transient workers, broadcasting music and banter in their languages - Spanish and Haitian French as well as English. Those interested in producing a program would be trained at Radio Conciencia.

Even the way the radio station was built $-\mathbf{a}$ collaboration among the Coalition, community radio advocates from Prometheus Radio, and the workers themselves - was a participatory activity. Over the course of four days, a radio station was built with the 
same spirit as a traditional barn-raising. Those with carpentry skills nailed together a studio console alongside those who had an interest in learning about carpentry. Twenty people comfortable with heights heisted up the antenna. Those with broadcast journalism skills taught workshops on interviewing and digital editing. Bilingually inclined participants offered English-Spanish (or vice versa) translations of workshops, technical talks and informal conversations. When the switch was flipped on Sunday evening and the red 'On-Air' light came on, participants could justifiably claim a contribution and a sense of ownership in Radio Conciencia.

Critics of participatory communication have pointed out that while it has been articulated on a theoretical level, very few specific guidelines actually exist for implementing models in real life situations (Waisbord 22). Participatory communication is seen as a long-term development strategy that often utilizes grassroots consensus decision-making processes and may not be suitable for urgent or short-term development situations. Another problem, some critics have pointed out, is that participation and access are ambiguous terms and it does not necessarily entail that all decisions maintain power equity. In some parts of India, for instance, women's access to radio simply means being able to listen to the radio (O'Connor in Servaes 174). 
Other critics point out that Freire's theory of pedagogical communication is based on group interactions and overlooks the role mass media play in promoting certain types of development (Waisbord 22). Because populations, even in remote areas, are constantly exposed to commercial media messages that may stand in opposition to a community's program's goals, the issue of mass media is especially relevant.

Counter arguments, such as the one Servaes formulated in 1996, point out that problems in carrying out participatory communication projects can be prevented. Recognizing that communities are not homogenous is an important aspect: "Participation does not always entail cooperation nor consensus. It can often mean conflict and usually poses a threat to existent structures. Rigid and general strategies for participation are neither possible nor desirable" (Servaes 23).

Developing a critical consciousness not merely towards mainstream media (Lewis 226) but towards all media is arguably the most important consequence of community involvement in a media project. For Lewis, this consciousness is achieved by directly involving people in media production. Participants begin to develop a "critical scrutiny" by becoming "personally responsible for the quality of information they spread and for the impressions they create" (Lewis 227). This newfound awareness leads participants to ask questions of the media they read and hear. Questions like, "Does the evening news 
portray the reality they experienced? Which sources are quoted, which are ignored? What roles and stereotypes are offered to the audience?" (ibid).

Of course, often the line between diffusion and participation is fuzzy within a radio station's infrastructure and programming. As will be discussed in the ensuing chapters, Radio Salus, this study's main model, is participatory in many aspects of its organizational structure, yet it does not offer citizens (non-students) the opportunity to take part in training or programming.

\section{SUMMARY}

This chapter began by looking at the history and evolution of low power community radio in North America. Based on principles of access and participation, locally based community radio also plays an integral role in offering an alternative to commercial and public radio. In the United Sates, the battle with the federal communications commission to secure community frequencies has been ongoing since the early 1990s. In Canada, Northern First Nations and Inuit peoples' trail radio and early community radio projects provided the basis under which a CRTC policy developed community radio as the third tier of the national broadcasting policy. Despite funding and 
sustainability issues, the commitment to nurture community radio in North America is tied to a belief that having access to a locally based and controlled communication alternative, particularly in the modern context of media consolidation, is a key component of a democratic media.

A consideration of community radio in the developing world necessitates a review of leading theories in development communications. There are two dominant approaches: the modernization paradigm and participatory communication. While both are still in use today, participatory community radio for social change has become the preferred approach by many international development organizations, such as UNESCO, and media development non-governmental organizations.

Whereas modernization theories tended towards diffusing information from experts in urban centres to "underdeveloped" people in rural areas, participatory communication for social change values local knowledge and culture while also recognizing the vitality of creating a culture of community-based participation, as in North American community radio models. While critics point out the lack of clear guidelines to implement participatory social change projects, the freedom for organizations to interpret exactly what participation entails at their particular station is, perhaps, another liberating aspect of the model. 


\section{CHAPTER III}

\section{RADIO IN AFRICA}

Before discussing the Rwandan context of radio, it is worthwhile to establish a broader context of African radio in the 20th century. The following section provides a general overview of radio in Africa, beginning with its colonial origins. The evolution of radio as a development tool can be broadly categorized as falling into two branches: the modernization paradigm and participatory communication models, as discussed above.

\section{African Radio Development}

Radio had steadily risen as the most popular mass medium in Africa since the 1960s (Banda 33). By the end of the 20th century, Fardon and Furnis estimate that 100 million people in sub-Saharan Africa owned a radio. As the price of a regular transistor began to drop (Fardon and Furniss 1), many African countries were well on their way to becoming distinct "radio driven cultures" (16-17). As a spoken word medium, radio is seen as a technology complementary to the oral-based traditions of African culture. For this reason and for its pervasive presence throughout Africa, radio is often seen by 
international development agencies as an ideal and trusted development medium that can empower local communities to respond to their own social, political and economic issues.

(Fardon \& Furniss 9; Banda 27). Further to this, radio transcends communication

problems posed by low literacy levels.

Radio was introduced in Africa just two years after it came to Europe, as a consequence of the many settlers in Africa. South Africa's first broadcast was in 1924, and in 1927 radio became available in Kenya. By 1934, four radio stations were broadcasting to white settlers in Africa (Brako \& Maja in McKay 33). When World War II erupted, colonial powers finally began broadcasting in local languages in Ghana (Gold Coast), Kenya and Zambia to keep families of African soldiers up to date with war news. After independence, governments kept broadcasting services centralized and based in capital cities. Radio was viewed by African leaders, as it had been seen by colonial powers, as a powerful administrative and development tool (Bourgault 81) capable of creating national integration and legitimizing their regimes. As outlined below, local radio was slow to come to Africa.

Although community radio has been present in other developing nations, particularly Latin America, since the 1950s, the origins of the concept in Africa is traced back to so-called rural radio and radio forums or listening clubs, beginning in the $1960 \mathrm{~s}$. 
The National Farm Radio Network (NFRF), a Canadian initiative, provided a framework that laid the groundwork for African rural radio models. Beginning as weekly broadcasts and ensuing discussion groups in rural Canada between 1942 and 1965, NFRF aimed to persuade Canadian farmers to take control over their own socio-economic situations (Sim, "The Farm Forum Story"). In 1964, UNESCO (with Canadian assistance) began implementing the rural radio model in Ghana, Zambia, Malawi and Nigeria.

The radio listening club model spins off from rural radio, but requires a higher degree of participation from members. For instance, through women's listening clubs based in the Mpika region of Zambia, 600 kilometres from Lusaka, members recorded their discussions about development issues (as well as requests for funding). These tapes were then sent to a radio producer in Lusaka who interviewed an official and recorded the response the listening club's issue. The series of discussions and responses were then edited into a single program that aired on national radio, ZNBC (Warnock 10).

Although rural radio models were recognized as a direct channel for the "voice of the people," McKay notes that although participatory, the programs relied on national, state-controlled media for distribution (McKay 27). Some critics have dismissed these radio models as government-controlled programs that do not adequately represent the 
concerns of all communities and lack any real political commitment (Opoku-Mensah 166).

Homa Bay Community Radio Station, a UNESCO-funded experiment in western Kenya in 1982, is cited as Africa's first community radio station (Fraser \& RestrepoEstrada 10). The government of Kenya supported the initiative aimed at decentralizing national media programming. The station was also a study in how radio technology could be implemented in a cost-effective manner. Homa Bay trained local people in a very underdeveloped region of Kenya to operate the station and create programs. After it had been on the air for more than two years, the government of Kenya closed down Homa Bay, accusing it of circumventing the promotion of English and Swahili as the country's official languages and inciting ethnic tensions (ibid). ${ }^{5}$

Despite its closure, the Homa Bay station demonstrated that community radio could be set up with equipment costs of less than US $\$ 25,000$, and encouraged UNESCO to promote community radio stations in other countries such as Sri Lanka, Ghana, Tonga,

${ }^{5}$ According to Fraser \& Restrepo-Estrada, Homa Bay broadcast for two hours a day in Luo, one of Kenya's principle languages but not that of the ruling ethnic and political group. 
Haiti, Cape Verde, St. Lucia, Trinidad and Tobago, Surinam, Guyana and the Philippines (ibid).

Throughout the 1980s, among UNESCO's mission was " free exchange of ideas and knowledge," and the promotion of "free flow of ideas by word and image" (Fraser \& Restrepo-Estrada, 2001). Under this banner, UNESCO launched a community radio initiative in which African governments were encouraged to decentralize national broadcast operations in favour of local satellite bureaus, so-called community stations (8).

The main reasons for this restructuring was that rural people, who made up as much as 80 per cent of the population, were not being reached by the national broadcasters due to a lack of common language and often the inability for urban producers to connect with rural residents' needs. Fraser and Restrepo-Estrada are careful to note that these early models, under control of national broadcasters, are clearly not examples of contemporary community radio in Africa.

In the 1990s, radio seemed to explode across Africa. This period of "radio pluralism" is seen as a direct effect of the democracy movement of the early 1990s that ended government monopoly over media (Myers 91), paving the way for the emergence of independent radio stations. As Fardon and Furniss note, "Diversification of radio broadcasting in Africa is very recent; even the pioneering efforts date from the 1980s and 
most initiatives are the product of the 1990s" (Fardon \& Furniss 3). Structural adjustment programs that forced governments to privatize media, leading to competition among new FM stations, also contributed to this (Myers 93). Finally, the support of international donors was another important factor in contributing to radio heterogenization in Africa: "Independent radios have been hailed and encouraged by bilateral, NGO and United Nations donors as a powerful force for community development and the promotion of human rights" (92).

Community radio in Africa continues to be promoted by UNESCO and a variety of international development NGOs. Mali, South Africa, Ghana and Burkina Faso are among those countries with established community radio stations. Barkina Faso is said to have pioneered certain aspects of community and local radio (Fardon \& Furniss 11). Local radio in Barkina Faso, according to UNESCO, dedicates 40 per cent of its airtime to news, 35 per cent to education and to training, and 25 per cent to cultural and recreational programming (UNESCO, 1997:150).

In Mali, community radio development was encouraged by the multi-party government established when the 23-year dictatorial rule was deposed in 1991 (Fraser \& Restrepo-Estrada 11). Consultations with rural area representatives revealed that residents felt alienated or indifferent toward national media (and the government's use of national 
media to impose development agendas). The new government was among the first of African legislators to liberalize radio and television, prompting stations to broadcast to local languages other than French, the language understood only by Mali's elite. Five years after media liberalization, Mali had 60 independent radio stations (Fraser \& Restrepo-Estrada 11) that often encourage communities to participate in radio program planning and production (McKay 35).

Mali is an exemplar of a phenomenon referred to by some as radio pluralism, a deliberate effort to foster a diverse radio culture. President Konaré of Mali describes some of the virtues of radio pluralism as follows:

Radio pluralism is an essential component in the deepening democratic process now under way: it allows people greater access to a diversity of information, and guarantees increased popular participation for sustainable human development...African states must speed up in the ending of the monopoly of the airwaves and give priority to national proponents of independent radio when allocating broadcast frequencies.

(President Konaré of Mali, 1993 in Fraser \& Restrepo-Estrada 11)

The "independent radio explosion" (Myers 92) gave birth to a diversity of private and community radio stations in the 1990s, particularly in South and West Africa. Bourgault notes that African radio was undoubtedly swept up in the broader context of political-economic liberalization (Bourgault 99). Referencing this period, Banda posits 
"there was a clamouring for a decentralization of national radio services as a means towards entrenching political pluralism and public access to the means of communication" (Bourgault $100 \&$ Banda 89).

While media liberalization opens the door for independent radio stations it also makes room for an overwhelming multitude of private broadcasters. Critics like Bourgault and Gumucio-Dagron accuse private media of diminishing local cultures and neglecting rural audiences:

The current spate of enthusiasm over newly burgeoning radio services in Africa seems preoccupied with urban entertainment services and middle-class political concerns over media access. Meanwhile would-be private media owners are concerned very much with potential profits. Unfortunately, little attention or energy has as yet been devoted to providing genuinely rural-based or "rural- friendly" broadcasting services to the media starved regions of the hinterlands. (Bourgault 100)

The majority of stations granted broadcast licences in Africa in the past twenty-five years are private commercial stations tending towards a diet of western music and entertainment programs that, arguably, gives "a mirage of variety and possibility of choice, though in reality only offers less in terms of contents, less information and less access and participation" (Gumucio-Dagron, 2001: 20). 
Despite the cacophony of radio voices competing on the airwaves today, radio plurality is essential if a media system is to have balance. Yet, as Frohardt and Temin note, "Plurality applies not only to the number of outlets but also to the number of divergent voices emanating from those outlets" (Frohardt \& Temin 389 in Thompson, 2007). In other words, radio pluralism not only requires a great number of voices, but demands a great variety of divergent perspectives. The importance of radio pluralism will be highlighted in the course of the next chapter; a lack of radio pluralism may have been a contributing factor in the Rwandan genocide. 


\section{Radio In Rwanda}

In Rwanda, history is often measured by referring to the period before 1994 and the period after 1994. The trauma of the genocide altered perceptions of national history in an indelible way. No longer is there a chronological chain of events that recount the country's rich history. After 1994, Rwanda's national consciousness became inextricably intertwined with the genocide as though bound in a limbo floating between 1994 and present day.

It is for this reason that the discussion of radio in Rwanda is structured in terms of the period before, during and after the genocide. Because, as a seemingly simple statement made by a young man who lost much of his family in the genocide, there is no going backwards in Rwanda: "After '94, everything changed."

\section{Radio in Rwanda Pre-Genocide}

President Habyarimana's government recognized the power of using radio to disseminate official messages through the national broadcaster, Radio Rwanda (Chalk 42) ${ }^{6}$. While the British Broadcasting Corporation, Voice of America, Radio France

\footnotetext{
${ }^{6}$ This essay appears in The Media and the Rwanda Genocide, a compilation of essays about the subject, edited by Allan Thompson in 2007. Since there is very little published
} 
Internationale and Deutsche Welle, international radio networks, were broadcasting to some extent in Rwanda, these services were not in Kinyarwanda in the early nineties (Sallot, interview, 2008).

The government had its reasons for promoting Radio Rwanda. Up until 1991, Rwandan politics consisted of a single-party state, the Mouvement Républicain National pour la Démocratie et la Développement (MRND), and Radio Rwanda was a direct channel for the president's announcements and messages. Radio Rwanda began broadcasting in 1961 and was widely seen as the "voice of authority" (Kamilindi 136). The station also broadcast news of deaths, linking families spread throughout the country (Des Forges 42). With a 34 per cent illiteracy rate and a limited newspaper circulation, Rwandans relied on radio (Waldorf 411).

In the early 1990s, Radio Rwanda's programming wasn't limited to benign public announcements and news from the head of state. As observed by Alison Des Forges, a senior adviser to the African division of non-governmental organization Human Rights Watch, Radio Rwanda was used in March 1992 to promote the killing of Tutsi.

information about Rwandan media's role in the 1994 genocide, almost all of the essays cited in this section are from Thompson's book. This work will cite essays by author in the citation and list titles with authors in the bibliography. 
In 1990, Rwanda had been attacked by the Rwandan Patriotic Front (RPF), a movement of Tutsi refugees and the refugee children, many of whom had fled to Uganda in 1959 when the Tutsi ruling elite were overthrown. President Habyarimana felt his power eroding and began to turn against the Tutsi living in Rwanda. Over the course of three days, the station repeatedly broadcast a communiqué apparently issued by a Nairobi-based human rights organization warning of an impending Tutsi attack in Bugesara, south of Kigali. Local authorities were interviewed on Radio Rwanda to further substantiate this claim. As recorded by the International Commission of Human Rights Violations in Rwanda: "Led by soldiers from a nearby military base, Hutu civilians, members of the Interahamwe, a militia attached to the MRND party, and local Hutu civilians attacked and killed hundreds of Tutsi" (Des Forges 42). After the initial RPF attack, and over the next three years, there were at least fifteen government-led massacres of Tutsi civilians (Des Forges 41-2).

Habyarimana recognized the importance of using media to mobilize citizens around his regime. These two elements were working together in Rwanda: radio and government authority. In a culture that puts a tremendous amount of faith in both these sources, Radio Rwanda was a respected voice in the country. Thomas Kamilindi, a Radio Rwanda journalist in the period before the genocide, observes: "People are raised and 
taught to take what they hear on the radio as gospel truth" (Kamilindi 136). According to Kamilindi, "authorities" kept tight editorial control over Radio Rwanda journalists: "It was difficult to do truly professional work as we were constantly faced with demands from the authorities on the manner which we should work, right down to the formulation of phrase" (Kamilindi 138). On one occasion, Kamilindi recounts being admonished by the minister of the Office d'information Rwandaise (ORINFOR), responsible for all stateowned media, for reworking the text on a government press release, a standard exercise for a professional journalist (ibid).

After the Bugesara massacre, a new government coalition was formed, as a result of the pressure put on Habyarimana from opposition parties in massive street demonstrations. An opposition member was appointed the new minister of information as part of this restructuring (Des Forges 43). Gradually policies were instituted to end the MRND media monopoly, opening the door for new radio stations.

Radio-Télévision Libre des Milles Collines (RTLM) was one of the 'independent' stations to break up the state-controlled media monopoly. Its inaugural broadcast happened just days after the signing of the Arusha Peace Accords, a peace treaty between the Rwandan government and the RPF, in August 1993 (Des Forges 44). The target audience of RTLM was ordinary citizens. The price of a share in the company was kept 
low to help accrue public support for this new private station, sold as a boon for media pluralism in Rwanda.

Pitched as a fresh alternative to stagnant Radio Rwanda, RTLM broadcasters presented in an informal, chipper tone and aired the latest in contemporary music. Whereas Radio Rwanda spun the same old standard tunes, RTLM played Congolese hits and dance music. The station quickly established itself as a trusted voice, broadcasting in a style that was described as sounding "like a conversation among Rwandans who knew each other well and were relaxing over some banana beer or a bottle of Primus in a bar" (Higiro in Des Forges 44). RTLM cashed in on the voice of the people moniker by airing listener's calls and music requests, and by getting out into the streets to interview people about topical issues. The amakuru ashyushye, hot news, was a particularly salient component of RTLM's daily programming schedule, promising more excitement than Radio Rwanda's dull newscasts. According to Prunier, even RPF soldiers tuned in to RTLM, often preferring it to their own "politically correct and rather preachy" Radio Muhabura (Prunier 189).

RTLM maintained a close proximity to official government lines by regularly broadcasting official voices while keeping its street-styled image. Considering that RTLM was, in part, backed by Hutu extremists with connections to Habyarimana's 
government, it's not a surprise that official sources were often employed to lend further credibility to RTLM's programming. That said, the station only had conditional ties to President Habyrimana and saw itself as upholding a cause (Prunier 189). As Monasebian notes, very early in the station's operations, RTLM established itself as an extremist broadcaster. At a RTLM shareholders meeting, held just three days after the station went on-air, one of the speakers was quoted as saying: "Aho umututsi yanitse ntiriva," meaning "No chance for the Tutsi" (Monasebian 309). The same message was carried on the cover of the July issues of hate journal Kangura. RTLM knew how to use "street slang, obscene jokes and good music to push its racist message" (Prunier 189).

RTLM rose to unprecedented power in a short period of time. Even authorities seemed helpless in stopping the tidal wave of hate surging from RTLM's studios. The director of ORINFOR, Jean-Marie Vianney Higiro, had tried on various occasions to call RTLM to task for "reckless broadcasts" (Monasebian 314) before April 7, 1994. Yet, Higiro became just another target of RTLM's vitriolic broadcasts, denounced on air as an inyernzi ${ }^{7}$ for collaborating with "the enemy" (ibid). Broadcasts were not limited to anti-

\footnotetext{
${ }^{7}$ Inyenzi, meaning cockroaches, was the name given to Tutsi guerilla soldiers in 1961-3 period. The term was meant to be derisive and diminutive and because, like cockroaches, the fighters tended to move at night. After 1992, Hutu extremists and allies started using the name again for RPF fighters and, then, for all Tutsis. (Prunier 402).
} 
RPF messages, but were clearly anti-Tutsi as well. In one broadcast, an RTLM broadcaster was quoted as saying "Tutsis and RPF are the same" (Monasebian 315).

RTLM became adept at giving the illusion of providing balance, even if it was only serving to back up false assumptions. Interviews with the 'other side' were conducted as in the case of Tito Rutaremara, a high official with the RPF, on January 6, 1994. Before the announcer began the pre-recorded interview, he embarked on long monologue intended to discredit Rutaremara, referring to him as "that tall Tutsi" and, according to anthropologist Darryl Li, reporting that "he was surrounded by other Tutsi drinking milk" (milk is synonymous with owning cattle and therefore wealth). After playing the interview, the announcer commented that Rutaremara answered questions in the typical RPF way (Li 97-8).

The Ministry of information, the federal agency in charge of media and communication, met with RTLM authorities in February 1994. Radio Rwanda actually televised this meeting in which the minister accused RTLM of inciting divisionism between Hutus and Tutsis. In a working document prepared by the ministry for the meeting, it was noted that RTLM would regularly "assimilate all the members of the RPF to the iniquitous Tutsi; assimilate the political problems of the country to the RPF; explain to the country that all the evil the country suffers is caused by the Tutsi" 
(Monasebian 317). In the video, the minister tells RTLM staff that Rwandese press should support democracy and peace and promote reconciliation: "As for the type of press that sets one ethnic group against the other, which sets the heads on fire, sets one region against the other, or causes strife between Rwandans and their friends, this has no place and should never have any in the country" (Monasebian 316). RTLM was warned that if it continued to use its airwaves as a "Hutus' mouthpiece" and refuse to be politically neutral, the "government may take measures against the RTLM" (ibid).

\section{Radio In Rwanda During The Genocide}

Following the assassination of President Habyarimana and President Cyprien Ntaryamira of Burundi on April 6, 1994, RTLM's radio transmissions rapidly became direct appeals for vengeance. In a carefully planned and systematic operation masterminded by Hutu extremists to overthrow the liberal Hutu government, the early days of the genocide were fuelled by propaganda about the Tutsis. Prunier compares this period in Rwandan history to the 1930s and 1940s when the Nazis circulated anti-Semitic rhetoric throughout Eastern Europe (Prunier 224). While Radio Rwanda, remaining neutral, broadcast information bulletins, RTLM was broadcasting direct incitements to 
"deliberately murder to 'avenge the death of our president' " (ibid) just hours after the presidents' plane was shot down.

It is difficult to overstate the role RTLM played in propagating hate during the 100-day period of the Rwandan genocide. Leading up to April 1994 and during the systematic killing of hundreds of thousands, RTLM essentially facilitated the attempted annihilation of the Tutsi population. The station legitimized killing through interviews, supposedly official sources and reports. According to Scott Strauss, who interviewed a large sample of the Hutu killers, RTLM's broadcasts reinforced the efforts of the authorities to organize Hutu for violence: "The radio broadcasts shaped the overall atmosphere in which the mobilization occurred and empowered the most violent killers" (Strauss, 2003 in Chalk 376). Had RTLM's signal been jammed or somehow prevented, current research states the mass mobilization against the Tutsi would have been seriously undermined (Chalk 376).

RTLM, whose listening range extended more or less across Rwanda, was the most popular radio station in the country during the genocide ( $\mathrm{Li} \mathrm{90)}$. As such, it was an extremely effective mobilizer for the Interahamwe militia and other groups dedicated to perpetuating mass killing. As Prunier notes, the instructions broadcast by RTLM announcers were direct incitements to carry out murder of Tutsi and Hutu moderates. 
Messages were as direct as: "You have missed some of the enemies in this or that place.

Some are still alive. You must go back there and finish them off" or "The graves are not yet quite full. Who is going to do the good work and help us fill them completely?" (Prunier 224 \& Li 90). These statements were spurred on by playing on distorted historical myths of Tutsi cruelty and treachery. RTLM announcers advised a "Kill or be killed" approach, although killing was thinly veiled as "work" and Tutsi were called cockroaches (Kimani, 2007 \& Li 93). Strauss, who conducted a series of interviews with prisoners, noted that the RTLM radio broadcasts were not ultimately responsible for the feeling of insecurity in Rwanda after Habyarimana's assassination and the civil war resumed, but they certainly contributed to it (Strauss in Chalk 376).

The general public's inability to distinguish between actual news stories and false claims by skilled RTLM animateurs frames a larger issue of media illiteracy. Li argues that while it is easy to assume a causal connection between the "ordinary farmer / citizen / radio listener" who was "open to manipulation, mobilization and stimulation" by RTLM broadcasts, the station appropriated ideologies that had previously produced ethnic divisionism in the country ( $\mathrm{Li} 93$ \& 97). During the genocide, Li argues, RTLM 
constituted an imagined community ${ }^{8}$ in which listeners became citizens. Not only did RTLM replicate the rhythms of a day's labour for Rwandans, it implicated listeners in the genocide by interviewing farmers at roadblocks or on the street about their particular contribution. Broadcasts were used to guide schedules and details of work (Li 101) and served to construct an everydayness attitude towards mass murder.

\section{Radio In Rwanda After The Genocide}

The meager media infrastructure that existed before the genocide had completely collapsed by July 1994. In the aftermath of the genocide, the RPF, who had taken power, began to carefully reassemble the ministry of information and the national media houses. Rather than creating a more pluralistic media, the government cited RTLM and hate journal Kangura as "cautionary tales about the dangers of too much press freedom and private media" (Waldorf 404). The RPF solution was to place even tighter reins on media

\footnotetext{
${ }^{8}$ Benedict Anderson theorizes that newspapers have contributed to the rise of nationalism through providing a ceremonial act. Reading a newspaper is an act of simultaneous participation by masses of people, although also an individual act. An imagined community is possible through the awareness that others are sharing in this act. Li argues that in Rwanda, radio is the dynamic site at which an imagined community occurs. (Li $107 \&$ Anderson 1991).
} 
than had existed before the genocide. It soon became apparent that the Kagame government, like its predecessor, would also use media to disseminate its own causes and promote its regime (ibid).

Independent media and alternative presses have proceeded with unsure footing since a 2002 criminal law restricted press freedom (Waldorf 407). Under this law, journalists and media companies charged with inciting divisionism or discrimination face imprisonment and fines (Rwanda 2002a: Article 8). Divisionism is defined in broad terms as "the use of any speech, written statement, or action that divides people, that is likely to spark conflicts among people, or that causes an uprising which might degenerate into strife among people based on discrimination" (Rwanda 2001a: Article 1). Opposition newspapers such as Umuseso, Umuco and Kinyamateka have been repeatedly targeted, and accused of inciting divisionism for publishing stories that point towards government corruption and nepotism or for challenging Kagame's leadership (Waldorf 410-12). Even The New Times, a government-endorsed newspaper, does not escape the Ministry of Information's careful watch. In 2007 , the editor in chief was fired for publishing a photograph that supposedly made President Kagame appear too thin. ${ }^{9}$

\footnotetext{
${ }^{9}$ The July 7, 2007 cover of The New Times featured the offending photograph, taken by Carleton University journalism student and Rwanda Initiative intern, David Kawai.
} 
For those living outside of Kigali, newspapers are often several days old by the time they reach smaller towns and rural areas. TV Rwanda, the state-run television developed in the 1990s, plays a limited role due to a lack of electricity in many rural areas and because many people can't afford a television set (Pasternack 4). Radio persists as Rwanda's most powerful medium. By 2006, 14 radio stations were on the FM band, four of which are private (Waldorf 411).

While Radio Rwanda and various private stations have news departments, journalism and communication in Rwanda has been adversely affected by a history of political and economic obstacles. The combination of journalists' questionable level of professional awareness and often limited training (Pasternack 3) and the RPF government's monopoly on information broadcast over the airwaves (Waldorf 411) has led to a critically underdeveloped media system. The proof of this underdevelopment is most evident in two ways: the absence of a "strong, independent pluralistic and professional media that can serve as a counterweight to government propaganda and manipulation" (Waldorf 413); and the absence of the "freedom to observe, criticize and comment upon government" without risking threats, arrests or imprisonment (Pasternack 2). 
After the genocide, National University of Rwanda (NUR) once again began to

look at introducing journalism and communication programs, a seed that had germinated in 1990. After 1994, journalists had earned a less than savory reputation in the public's mind and, as Pasternack notes, "there was a need for educating a new generation of skilled and responsible communicators, both for the nation's mass media and to bring information (health, social issues, and agriculture) to the broader population" (Pasternack 3).

In 1996, NUR launched "Ecole Supérieure de Techniques d'Information" a fouryear program offering journalism skills and public relations or a three-year special licence program for students who had degrees in other areas of study. While it was a start, the program proved overly theoretical and lacking in practical skills training and in "debate and discussion about the media's role in society" and "ethics and responsibility" (Pasternak 4).

In 2000 , the school was redesigned to focus on practical training. The renamed "School of Journalism and Communication" (EJC) is based around two professional streams: journalism, or communication and development. According to Pasternack, who played an early role designing the curriculum: 
The goals of the new curriculum are to provide $R$ wanda with a well-trained and responsible pool of journalists to work at its various mass media and to provide a supply of communications professionals able to use their skills in areas such as health, environment and agricultural communication. Both programs have a practical -- rather than theoretical -- basis. Both programs provide students with a broad-based general education, combined with the necessary communication skills. (Pasternack 4)

As of the 2002-03 academic year, there were a total of 62 students divided into three separate classes. In 2008, the number of enrolled students has more than doubled. According to Margaret Jjuuko, the deputy director of EJC, 160 students are currently enrolled in the school. In 2008, numbers are unprecedented as 75 students were accepted into the first year of the program.

\section{Community Radio in Rwanda}

For journalism students to ply newly acquired skills and develop practical

training, having access to media outlets is essential. Journalism departments often have collaborative relationships with campus-based community radio stations at their respective universities. CKCU, the radio station at Ottawa's Carleton University, airs Midweek, a weekly current affairs program produced by journalism students in the 
undergraduate and graduate programs. Three times a week at CKDU, the radio station associated with Dalhousie University in Halifax, journalism students at King's College produce the news and current affairs program, The Radio Room.

After a 2002 Rwandan press law opened the doors for private broadcast licensing, the idea of a radio station on the National University of Rwanda campus was born. Steven Pasternack, a visiting professor from the United States and a INESCO consultant, began developing the community radio project with the EJC administration. The envisioned radio station would be the first major station in a city outside of Kigali. In a proposal, the station's objectives were laid out:

We propose a station at the national university (NUR) with the goals of training future Rwandan broadcasters; enhancing and diversifying the radio programming; and enhancing democracy building in Rwanda. Target beneficiaries are the general population of Rwanda, who will benefit from access to an alternative to state radio, with a variety of programming and professional, responsible opposing viewpoints on the issues of the day. (Pasternack in UNESCO, 2003)

Radio Salus went on the air in November 2005, broadcasting from an off-campus house owned by the university. The focus of the ensuing chapters is the evolution of Radio Salus, Rwanda's first community radio station, as a training ground for journalism students, staff and the general public. 


\section{SUMMARY}

Before undertaking a close examination of Radio Salus, an understanding of the context from which the station emerged is essential. This chapter laid out a general history of broadcasting in Africa, introduced by colonial powers in South Africa and Kenya. After independence, African leaders quickly seized upon opportunities radio offered as an effective mobilization and development tool. Often with international financial support and expertise, national radio has been employed to disseminate information. Participatory models have had some successes in the form of radio forums and listening clubs, particularly in Ghana, Zambia, Malawi and Nigeria.

The 1980s marked a period of media pluralism in which UNESCO was at the forefront of developing independent loeally based community radio stations. The 1990s signified an explosion of radio in Africa in which a myriad of private radio stations were granted licences. Credited with contributing to a more pluralistic media, these private radio stations are arguably also chipping away at local culture by broadcasting primarily western popular music.

In the early 1990s, Rwanda's media were still largely controlled by MRND, a one-party government, and were limited to state-run outlets, ideal for promoting the 
regime and disseminating official information. In 1993, as a result of pressure from the public and newly formed opposition parties, a coalition government was formed.

Restructuring and policies that followed paved the way for new broadcast licensees to break up the MRND media monopoly.

The tragedy of Rwanda's attempts to diversify media was its inability to enforce regulations and rein in RTLM, the first private radio station in the country, when it began broadcasting propaganda and discriminatory remarks against the Tutsi and moderate Hutu population. In the evening of the assassination of the presidents of Rwanda and Burundi and the 100 days that followed, RTLM incited listeners to do their 'work' by killing their fellow Tutsi citizens.

In the aftermath of the genocide, the media development has been stilted by the RPF government's hesitancy to loosen state control. Citing the emergence of media pluralism as having led to the divisionistic programming of RTLM, President Paul Kagame's government has at times displayed a hostile attitude towards independent media and professional journalists, despite official rhetoric stating otherwise.

The creation of a professional journalism school at the National University of Rwanda and the ensuing birth of Radio Salus, the country's first community radio station, represents a new dawn for Rwanda's media development. 


\section{CHAPTER IV}

\section{RADIO SALUS}

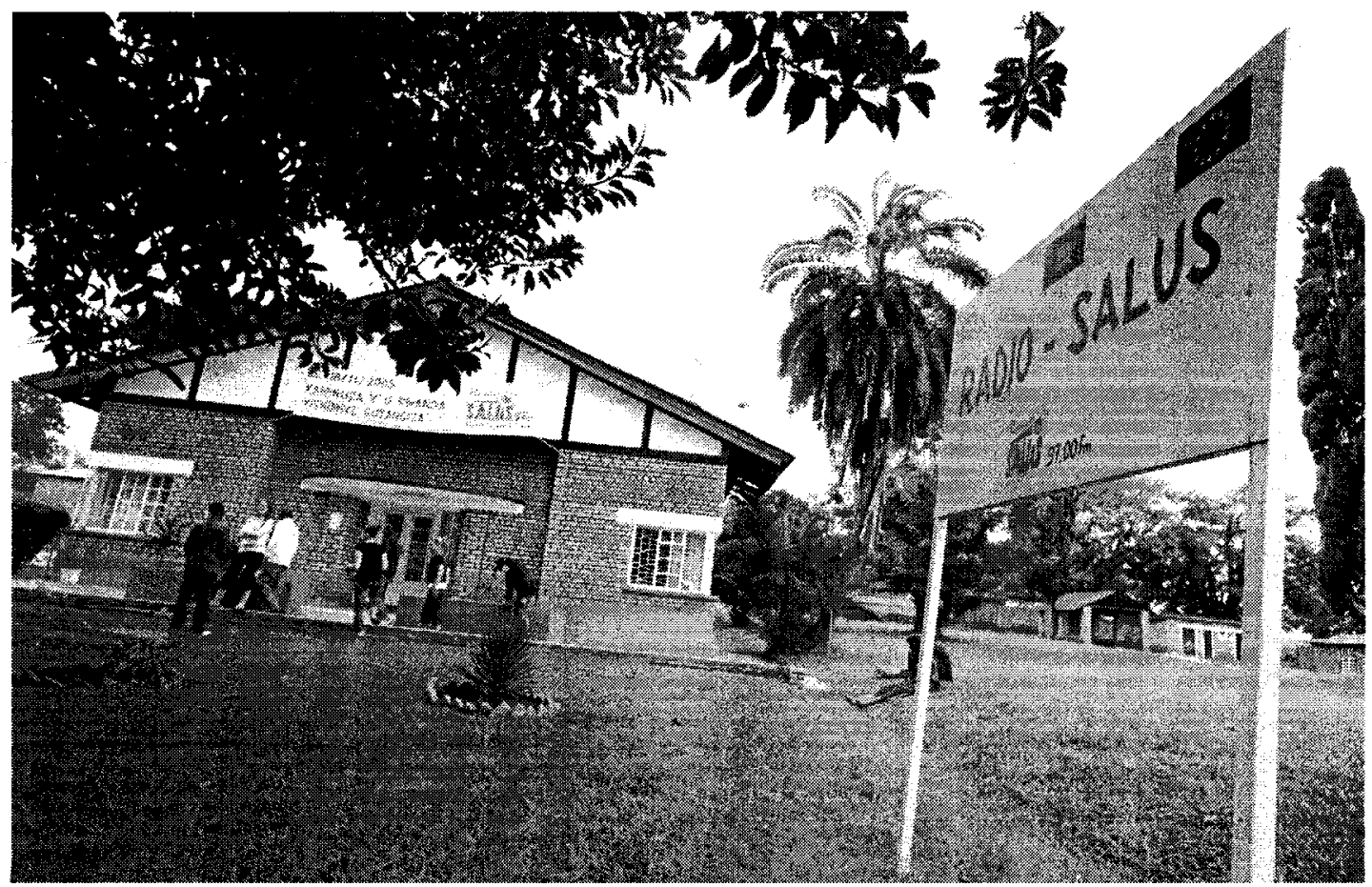

Radio Salus

photograph by David Kawai

When you hear about how people are talking about Radio Salus, it's like an innovation in media in Rwanda. It's seen as a professional station and for many Rwandans now, it's a source of educational programs. It's like we are somehow thought of as different radio in Rwanda.

(Havugimana, interview, 2007)

From the National University of Rwanda campus, it takes about thirty minutes to

walk along the black paved road to Radio Salus headquarters, located across from the

local football stadium. This road is the major artery connecting Butare to the rest of the 
country. Although some journalism students tend to complain about the lengthy walk, the fact that Salus resides in its own building, a distance from the main campus, has advantages. Being situated in the centre of town, Salus is easily accessible to the surrounding community. Local citizens frequently stop by the station for a tour, to request songs, or to drop off music and letters for a particular journalist. Salus's downtown building, a house owned by the university, has given it a prominent profile in Butare.

The menagerie of people and activities encountered on a typical walk through town is most likely a representative picture of Radio Salus's listening audience: teenage security guards, young mothers with babies, business professionals, students, store owners and villagers carrying produce into the town market. From the beginning, Salus has aimed for a diverse cross section of listeners. As the self-appoiuted "voice of the people," it attempts to reach a target audience across economic and social lines and into the often media-starved rural villages.

The word salus is taken from National University of Rwanda's Latin motto, Illuminato et Salus Populi, meaning "the light and salvation of people." The mission of Butare's first radio station is to "enhance and diversify radio programming and democracy building" and to simultaneously "train future Rwandan broadcasters." This 
chapter examines how Radio Salus, a community and educational radio station, attempts to fulfill its ambitious name. The first section examines the station's founding goals, its programming, its staff and volunteers. The second section addresses the station's system and methods of training student journalists and its relationship to the school of journalism and communication.

\section{First Steps}

Steven Pasternack, the head of journalism and mass communication at New Mexico State University, envisioned a campus radio station playing an integral role in nurturing a new generation of professional journalism in Rwanda. Pasternack made numerous trips to Rwanda between 2000 and 2003 to teach journalism press law and ethics at the NUR in Butare (Thompson, 2007; interview with Eugene Hagabimana, 2007). During his tenure as a Fulbright scholar within the school of journalism and communication, he proposed a revised curriculum. The four-year program emphasized hands-on training in television and radio equipment, broadcast and print writing, studies in communication theory and journalism ethics. As well, students could take a variety of courses from other disciplines, including political science, philosophy and languages. 
Pasternack criticized the school's original curriculum for being overly theoretical when there was clearly a need for "skills-based education and training" (Pasternack 4).

Canadian journalist and media consultant Michelle Betz also played a role in expressing a vision and practical guidelines for Salus. As an Knight International Press Fellow, Betz first came to Rwanda in 2003 to teach at EJC. She notes students' lack of practical broadcast skills:

They'd had absolutely no practical experience in broadcast, in part because there was no equipment nor any faculty to teach. I was the first person at EJC to teach TV and radio courses. We had three (or four) small DV cameras and one adobe editing system on which to edit. It was a challenge, to say the least. (Betz, interview, July 2008)

According to Betz, "the students wanted to learn, but they had no equipment on which to learn and no lecturers with broadcast experience" (ibid). The lack of faculty Betz refers to was the complete absence of native Rwandan journalism professors at the school.

Through international programs, visiting professors such as herself, Pasternack and others from the British Broadcasting Corporation (BBC) and Radio France International (RFI) and a few independent journalists came for short-term teaching assignments, often just for a couple of months. When there was a broadcast professor visiting, as Betz notes, the lack of equipment made it almost impossible for students to do practical work. 
As an experienced broadcaster, Betz was brought into Pasternack's discussions about a radio station at NUR. They both believed that a radio station would be an ideal training ground for broadcast journalists. A licensed radio station would jump start students into the working world and provide a desperately needed alternative voice on the Rwandan airwaves. Pasternack was instrumental in articulating the objectives of the proposed radio station and pursuing start-up funds from UNESCO. He died suddenly after retuning from a trip to Rwanda in 2003, but his vision had taken flight. Radio Salus went on the air in November 2005.

During the first two years, Salus's signal reached only half of Rwanda's population and broadcast just sixteen hours a day. Yet, from the beginning, Radio Salus had its sights on national media development so perhaps it's symbolically important that Salus became the first significant broadcaster outside of Kigali. While a myriad of private radio stations sprang up in Kigali between 2002 and 2005, Salus was based at the National University of Rwanda in Butare, the country's second largest city. Salus, while claiming status as both a community and educational station, was determined to reach beyond the borders of Butare. The first one kilowatt transmitter, installed in Southern Province, would be followed by a second in Kigali, thus expanding Salus's signal to more 
than three-quarters of the country and broadcasting, via night-time automation, twenty-

four hours a day, seven days a week. ${ }^{10}$

\section{Salus Organization}

Although officially a private licensee owned by NUR, Salus remains editorially

independent from both the university and the government. The station provides a training

function by offering journalism students an opportunity to pursue hands-on broadcasting

experience. The objectives of Radio Salus, as laid out in the original UNESCO

application and still included in the current station documents, are as follows:

- Provide the community of Butare (Rwanda's second city) with its first radio station, and the first significant broadcaster outside of Kigali

- Build in Rwanda confidence regarding private radio as a viable means of mass media

- Provide diversity of programming for the population of Rwanda

- Enhance community debate through on-air discussions of significant local issues, such as health, agriculture and environment

- Improve the curriculum of the School of Journalism and Communication through the integration of the radio station into appropriate courses

- Provide a hands-on opportunity for direct radio experience for students at the university,

\footnotetext{
${ }^{10}$ According to Salus literature, the signal "reaches the whole south of Rwanda from East to West. Radio Salus also reaches Kigali, the Western and Northern provinces of the country."
} 
both inside and outside of the School of Journalism and Communication

- Offer students the opportunity to become trained using new digital broadcasting technologies

- Provide a broadcast media advertising market for businesses in Butare

These objectives inform Radio Salus's programming content and its organizational ethos.

Up until 2007, the station depended almost completely on the original

UNESCO/Japan Funds-In-Trust Co-operation contract, signed in 2003, under the

framework of the project "Radio Station at the National University of Rwanda."

UNESCO invested approximately US $\$ 500,000$ into station start-up, equipment and

training of staff and students (Betz 4). Since then, Salus has been able to generate some

advertising revenue through sponsors such as the national telephone company, MTN/

Rwandan Cell, and Amazi ya Huye, a Rwandan bottled water company. According to

Havugimana, advertising has contributed about twenty per cent towards the overall

annual operating budget. This includes program sponsorships, such as the one paid by

American-based USAID for a radio drama produced regularly about coffee farmers and

agriculture. NUR is also contributing some funds to help sustain Salus and pay staff

salaries. As with community radio stations across the globe, financial stability and

sustainability is an on-going issue. 
The programming schedule, according to Betz, was primarily created by

consulting with students about the kinds of programs they thought should be produced.

According to Salus director Aldo Havugimana, the schedule has evolved since then as the station receives feedback from listeners on topics and the kinds of programs they would like to hear. It's also worth noting that each time Salus sends an email as a response to a listener, an automatic message is included that asks the listeners to give feedback about what they want to hear on Salus.

As at most community stations, the smorgasbord of programs includes a wide variety of music shows (in Kinyarwanda, French, Swahili and English) in which a student deejay spins discs and takes requests. At least one Salus staff member refers to these programs, albeit affectionately, as "stupid shows" due to lack journalistic skill needed to produce a music program. Yet, these popular programs receive large numbers of requests and song dedications sent to the studio through SMS (text messages), emails, post and phone calls.

Talk shows also seem to receive great support from the listening audience. Dispersed throughout the weekly schedule, a rotating programmer is responsible for thinking of a topic. She introduces the topic and the listeners are invited to call in or send a message with their thoughts. 
Spoken word programs ${ }^{11}$ are weekly or bi-weekly shows produced on a specific

topic. Examples of regular Salus spoken word program topics include agriculture,

environment, AIDS, history, sports and sexual health.

Finally, newscasts are a significant focus of Salus Radio programming. Five days

a week, Salus produces two thirty-minute newscasts in Kinyarwanda. Each morning a

news team consisting of approximately six reporters meets with the news director,

Eugene Hagabimana. The newscasts are a tight blend of national news, international

news and fresh news voicers. The second evening newscast sometimes includes

developments in a story that was being followed in the earlier newscast.

\section{Staff, Students And Training}

Radio Salus has four full-time staff members: the director (manager), a news

director, a production director and a program director. Part-time staff includes a

technician, a bookkeeper and a sports director. Staff members are accountable to the

director, who is, in turn, held accountable by a Council of Advisers, similar to a board of

${ }^{11}$ Spoken word is an established term in Canadian community and campus radio to denote more in-depth investigation of an issue or a topic. Spoken word content varies and can include, feature interviews, documentaries, and specialized programming on particular issues such as history, agriculture, HIV, etc. 
directors, consisting of four NUR -representatives, a representative from the Ministry of Information, and five members from civil society. The NUR members are composed of the Dean of the School of Journalism and Communication; the NUR rector (president); the head of NUR's Research Commission; and representative from the NUR students' union. The civil society members include a representative from a "Butare association for women empowerment"; "a representative from Butare urban cooperatives"; and a "representative of rural cooperatives" (Salus Outline, 2007).

Where the station infrastructure begins to diverge from a typical North American community-based campus station is the way in which programmers are recruited and organized. In 2005, twenty-six senior level NUR students were recruited as Salus trainees. Those chosen participated in a month-long radio production training session with Canadian media consultant Michelle Betz. As per the original contract between UNESCO and NUR, each of the trainees would receive a monthly salary of US $\$ 50$ for one year (Betz, 2006). The idea, of course, is that trainees would continue to work at the station in various programming capacities. UNESCO agreed to provide the salaries for that particular year. Most of the students were recruited from the journalism program, but there were trainees from other faculties, such as law. 
First-year students were not included in the original recruitment. One problem with the system, noted by Betz in a 2006 report, was that at the end of the academic year, many of the students were moving from Butare, thus taking their skills with them. She returned several times between 2005 and 2007 to train staff and students.

The ultimate goal was to be able to have the senior students be capable of training new incoming students so that I would no longer be needed. So, the first year I went several times to train - focused on writing, editing (which is what they seemed to really want), finding stories, interviewing skills etc. I tried to cover as much as I could in the limited time I was there. It's been great now to see how the senior students are now assisting with the training of incoming students. (Betz, interview, 2008)

The training sessions for student journalist focused heavily on radio production: using recorders, microphones; interviewing skills; digital editing on Adobe Audition; and research skills for spoken word programs. Currently a second-year EJC student, Jean de la Croix Tabaro participated in one of the first training sussions during his first year. Tabaro now co-produces a weekly agriculture program and is a news reporter. He says the skills he learned from Betz were instrumental to his journalistic development. In a interview, he said, "Betz gave us the first skills on radio, how to make a good voice on the radio, the position to take in front of the interviewee, ambient sounds. I remember she showed us, she made us listen to an example of ambient sound, she gave us the sound of a cow she (recorded)" (Tabaro, 2007). 
From an observer's standpoint, the progress made by Salus students and staff is

remarkable. On any given day, reporters are busy editing audio, researching news

headlines and writing scripts in the Salus computer lab of five machines. Yet, the Salus

director thinks there's still a great need for sustained training.

There is not sufficient trainers and when they are booked, they don't have enough time to follow up on the training they have been doing. We should, the school should have a number of permanent trainers, lecturers who are in charge of follow up training. It's like, when you give someone a course of forty-five hours, they come to the station, they start working but they still need a follow up for more. So now it's like we need a longer period of training instead of short trainings, then letting people go to the field without supervisors. (Havugimana, interview, 2007)

According to Havugimana, while staff members are theoretically now in charge of training new recruits, they are often overbooked with other responsibilities that go with simply keeping the station on the air: daily newscasts, feature spoken-word programs, producing advertising and sponsorship programs, fixing equipment and keeping track of field equipment.

Ideally, of course, senior staff such as production director Terence Muhirwa would have time to work alongside new student journalists. Muhirwa certainly recognizes the importance of establishing a one-on-one rapport with journalists throughout the process of preparing a feature program: 


\section{When the student is responsible for a show, before going to collect}

information, I meet him and we talk about what he is going to do. If there is a show about gender, he comes and we talk about who he is going to interview, we talk about the situation, we talk about the milieu, where they are going to, yes, all those. When he comes from the field, I help him to select what is necessary and what is not necessary and to edit and to (then format the show). (Muhirwa, interview, 2007)

Unfortunately, as with many overtaxed staff in a non-profit organization, usually

there's simply not enough time to do check-ups on training once recruits are given their initial training. In this case, some staff members are relatively new to field recording equipment, audio editing and radio technology, and so it's not surprising to see common problems springing up in the editing room. A recurring technical issue is overly loud or high audio levels. This happens for various reasons: a microphone or recorder is turned up to high and the interviewer is not wearing headphones to monitor and properly adjust levels. The result, if not compensated for when possible in the digital editing stage by lowering levels, is the broadcast of distorted, low quality audio clips.

Since the original recruitment of trainees, Radio Salus has gained a popular profile within the university community. According to Dominic Nduhura, EJC director, students two years ago were less interested in working with Salus. These days, there is greater interest, both within the journalism faculty and the general student body, in being part of Radio Salus. As Nduhura notes, "a selection process has to take place to choose 
who is the best. Not everyone is good enough to go into radio" (Nduhura, interview, 2008).

The fact that Radio Salus has been on the air since 2005 and has already been rated as one of Rwanda's top three radio stations is a part of the new popularity among students. There's also an undeniable glamour of being on the air that students can be attracted to. However, another attractive aspect of working at Salus is the monthly stipends, originally paid by UNESCO, now paid by NUR. These salaries have been a bone of contention for students working at Salus. In 2007, some students demanded that the salary be increased. Other students who came to Salus through other channels besides the original recruitment were doing the same work, yet not being paid at all.

In early 2008 , a new recruitment and training system was introduced. It recruited first- year students to begin an intensive training session. Rather than bringing in an expert international trainer, sessions were conducted in-house by experienced upper-year students with Salus experience. To a limited extent, Canadian journalists teaching at EJC or part of the Rwanda Initiative program were also involved in the training sessions. Training was completed in workshop style intervals over the course of six months on interviewing for radio; using recording equipment, and digital editing; preparing news voicers; and journalism ethics. Conducting the sessions in-house created a sense of self- 
reliance within the Salus community. The problem, according to the Salus director and first year students, is that there wasn't any access to field recording equipment to practice new skills (Havugimana, 2008).

Yet, perhaps the bigger issue in the 2008 first-year training process was the manner in which students were recruited. According to Nduhura and Havugimana, as well as technician Fabrice Nice Neza, selected students went through a rigorous selection process. From an initial list of more than one hundred interested students, a first selection was made based on academic merit. Fifty students, both male and female, were then chosen to write an exam as well as complete an oral interview with Salus staff. The students were graded (by Salus staff) and the twenty-six students with the highest scores were invited to participate in Salus training (Nice Neza, personal interview, 2008).

Based on exam and interview scores, the original twenty-six students were all male. The committee overseeing the interviews and the exam were also male. According to Neza, who participated in the selection process, questions were posed in the oral interviews to test student's ability to think on their feet and to articulate what it means to be a journalist. The written exam, however, seems to be based on random trivia rather than any kind of knowledge of journalism. Questions whether Cleopatra is from Egypt or Rome and if "real twins" share the same fingerprints seem to be more of a weeding-out 
exercise than a legitimate test in journalistic aptitude or determining whether a student will succeed at Radio Salus. The exam, in its original form, is included as Appendix A in this study.

Despite the hurdles of making it through the Salus door, there are also examples of students who have developed broadcast journalism skills by coming through the backdoor. Prudent Nsengiyumva was in first year when he approached Salus staff about volunteering as a reporter. In the past year and a half, he has become one of the station's most valued show hosts and news reporters. The experiences and goals of Nsengiyumva and others working at Radio Salus will be introduced in the next section.

The relationship of Salus to the school of journalism and communication at NUR is, at the time of writing, ambiguous. While the radio station has become an essential branch of the school's broadcast training, there has been little, if any, formal recognition of the partnership. Before Salus, EJC operated a broadcast studio on campus. The station was never actually on air and what equipment it possessed was seriously archaic. The broadcast equipment inventory amounted to a reel-to-reel tape player and razorblades. After the establishment of Salus, the school seemed to rely more and more on the use of Salus equipment for students enrolled in radio production courses at EJC. 
Since Salus is, to a large extent, an autonomous organization separate from the school of journalism, it can be a strain on its existing resources to constantly share equipment with the journalism school. Nduhura, the director, sees the relationship as a cross-pollination in which both organizations are sharing resources. He obviously recognizes the value of what Salus offers students in and out of the classroom training: When you meet some second-year students, you can't believe they're only in second-year because they know how to report, they know how to deal with news. When they reach their third or fourth year, they are really skilled, mainly because of Salus. So, it is very, very enriching. They are goinginto the field and meeting their elder brothers and sisters. And they use, for instance, broadcast software. They learn that software while they are still in their first or second year. (Nduhura, interview, 2008)

While student with access to Radio Salus have dramatically improved practical radio broadcast skills, the lack of formal agreement between the station and the school is a point of frustration for some professors.

Students involved with Salus tend to think of their responsibilities as employment, and in many cases students are receiving monthly stipends to carry out duties. It's a common occurrence, therefore, that students put priority on Salus duties over classroom attendance. Long-time CBC journalist Joan Leishman spent two months in Butare teaching the performance aspects of broadcast journalism in the spring of 2008. During the course, she became increasingly frustrated by what seemed to be a lack of dedicated 
students. In an end-of-term wrap up letter addressed to Nduhura, she writes, "While many of the students in this course attend class regularly and show up at the appointed times, at least half of the students are undisciplined and are consistently late." She goes on to point out that Radio Salus was the reason that students did not attend all classes: "Several of my students have regular commitments at Radio Salus which they feel come before attending class and course work. One of the students missed the first 16 hours of the course because she was on a trip for Radio Salus" (Leishman, 2008).

Leishman's frustration is not an uncommon theme among visiting international professors. Brought to Butare through the Rwanda Initiative to teach courses at EJC in six to eight weeks, they find it difficult to cram in an entire term of work into such a short time period: "Much of our course work consisted of practicals in radio and TV announcing. These skills are built upon incrementally. I tried consistently, and almost on a daily basis, to repeat missed lessons, but as you know, there is never enough time" (ibid).

From the perspective of the journalism school's administration, a clear solution has not yet been found. The way Nduhura sees it, as the director, Salus and the school have a mutually beneficial relationship: "We can't say ‘you students, you don't have to go to Radio Salus,' but, at the same time Radio Salus can't say, 'enough is enough, 
because we are causing you problems, we're going to stop and use other people.' They cannot have their own journalists and pay them. Using our journalism students is very cheap" (Nduhura, interview, 2008). Nduhura has suggested that Salus staff visit other journalism schools with radio stations, such as Uganda's Makerere University in Kampala, to gain insight on how others are managing the issue vis a vis students' classroom and station responsibilities.

\section{But, Seriously}

It might be the ultimate insult to tell a Rwandan journalism student that they are not serious. In Canada, being overly serious is often seen as lacking a sense of humour, sparking the advice, "Lighten up" or "Don't be so serious." Yet, in Rwanda, not being serious has negative connotations denoting a lack of commitment and discipline. An example of how not being 'serious' has negative implications at Radio Salus is with regards to the use of field recording equipment: digital recorders, microphones and headphones. Over the past couple of years, Salus has acquired a fair number of recording kits through various international donors, such as Journalists For Human Rights. While technician Fabrice Nice Neza does an admirable job of keeping an inventory of 
equipment, there doesn't seem to be any systemic sign-out system. Students often have to literally beg Neza or other staff members for access to field recording equipment. If they are granted permission to use the gear, there is no method of accounting for the signed out equipment and it is frequently given out without any kind of protective bag. Needless to say, lost and damaged gear is common.

On one occasion, a second-year student needed to record his voice for a news report. In the same computer editing room as at least five other reporters, this student asked everyone to be quiet so that he could record his voice into a recorder. While this is a terrible audio practice - recording in a room full of people without headphones -- this method of voice recording is an accepted technique by Salus staff and reporters. When it was suggested that the reporter find a quiet place to record his voice with the use of headphones to monitor his levels, he shook his head and said the technician would not let him use the headphones. The technician, who was standing close by, responded with, "When you get serious, maybe I will give you headphones. If I give you headphones, (you'll) take them to the market and sell them" (personal observation, 2008).

To be fair to the part-time technician who is responsible for keeping all equipment in good working order, including a dozen digital editing computers and an internet audio streaming system, Salus field equipment often gets lost or broken. Nice Neza is being 
protective on the gear, based on bad experiences with signing out equipment. Yet, students are then forced to compromise the quality of their work simply because they can't access the necessary equipment.

On the other end, to be told one is serious is taken as a compliment. First-year Salus reporter Pamela Mudakikwa describes positive public reactions to Salus programming: "So when people listen to Radio Salus they are excited, they are surprised to hear (interesting programming) and they say 'you guys are learning, you are serious" (Mudakikwa, interview, 2007). Clearly, being serious is equivalent to being thoughtful and skilled.

Tied into the conversation about the perceived seriousness of student journalists at Radio Salus is the notion of professionalism. The majority of Salus staff members and student journalists interviewed for this study used the word 'professional' when describing both their personal and collective goals for their work on Radio Salus. Station director Aldo Havugimana says his vision for Salus is not necessarily for it to be the best radio station in Rwanda, but to be a professional radio station, different from all others in the country. When pressed to explain, Havugimana says "a radio station that's guided by journalistic principles rather than any other interferences" (Havugimana, interview, 2007). 
Student journalists also say they want their work to be professional and for Radio

Salus to have a professional reputation. For Mudakikwa, professional means careful

research and "complete information" presented in a program:

For example if you had to talk about a situation you have to be sure that you talked to (all) concerned people. You have to push, talk to as many as possible just to get what is the real thing. So when I say professional I mean research, I mean complete information, not from one part of the people, one group of people, but every concerned people, and its not just asking questions, you have to know the techniques. (It's also important to be) on time, knowing how to ask questions until you get what you want. (Mudakikwa, interview, 2007)

Although Mudakikwa was just eighteen at the time of this interview, she regularly hosts talk shows that debate controversial issues, such as female dowries and domestic violence. In this format, part of presenting all sides of an issue is giving ample airtime to listeners. After presenting her research, listeners are given the opportunity to call in. Prudent Nsengiyumva, her classmate, agrees that creating a format where Rwandans can intelligently discuss and debate controversial issues is part of what makes Salus

professional:

So, I was discussing, 'is it really a must that when you don't pay a dowry, you can't get a wife?' So, the listeners said, 'No, that was in the past! Today you can be married without giving anything...just when you have love, you can get married and live together. The dowry is no longer a must.' So, it was big, big discussion. And it is still a long discussion because listeners wanted (to continue talking about it) the next week." (Nsengiyumva, interview, 2007) 
Culturally, certain issues are taboo discussion topics. Professional journalism, in so far as these students are concerned, encourages public dialogue.

The daily newscasts are an important focus of Radio Salus's ambitions towards professional broadcast journalism. Two thirty-minute magazine-styled Kinyarwanda newscasts are presented at five and eight each evening during the week. Each newscast gives international and African news headlines, and follows two national stories with voicers (a radio term for a story in which a reporter assembles clips from sources with their own narrated script).

In the case of presenting news headlines, sources, most often from the internet, are attributed in the report. For instance, an update about the International Criminal Tribunal for Rwanda in Arusha, Tanzania was attributed to three news agencies: L'Hirondelle, AFP and Reuters.

Newscasts during the week of November 22, 2007 were translated to English for the purposes of this study. In Appendix B, the program schedule, gahunda y'ibiganiro, illustrates prime-time slots for both newscasts. In one week, national stories included creating a green space on urban land (and keeping trespassers off); how Catholic medical centres (and reproductive health clinics) are handling reproduction and STDs; a breaking news update about a murderer of genocide victims who had been sentenced to life 
imprisonment (full story to be followed in later news); policy issues within Foundation for Genocide Survivors' programs; a feature about a school for homeless children celebrating its tenth anniversary; an adult literacy program; and AIDS youth education during Umuganda (national work day). In each story, reporters included at least two (in most cases three) sources.

A full transcript of the Rwandan news stories from Salus's early evening newscast is included as Appendix $\mathrm{C}$ in this study. As evident in this representative example, stories run twice as long as the typical $\mathrm{CBC}$ news voicer (which is generally a minute and a half long). In a story about the street children school, the reporter uses four sources. Salus journalists are expected to have more clips from ordinary people affected by the issue rather than using mainly "official" voices of politicians and municipal authorities (Havugimana \& Hagabimana, interview, 2007 \& 08).

These newscasts are balanced and informative and certainly embody the professional journalism Radio Salus strives to produce. According to news director Eugene Hagabimana, reporting in a country like Rwanda is challenging: 
You cannot work as a journalist in a Third World country without meeting problems. For example, I made a story about problems in Rwandan political party, the Liberation Party. They have two sides, a confrontation between those two sides. In the story, I asked one side and then the other, and the current president called me and asked, 'Why did you give the microphone to the other side?' If I have to do my story, it should be balanced. (Hagabimana, interview, 2007)

Rwandan journalists, of course, face problems even more precarious than annoyed sources. In December 2007, a photographer from The New Times, Rwandan governmentendorsed national paper, was beaten and detained for taking photographs of the arrest of street vendors. Several other Kigali-based journalists stepped up and said the incident was not isolated - that journalists around the country frequently face unprovoked harassment from police (Maughan, The New Times, 2007).

While media freedom is not the focus of this particular study, it does serve to highiight the drive and determination of Salus staff and student journalists to produce high-standard news coverage in the face of adverse conditions. A more common struggle faced by Salus journalists in the field, however, is simply getting regular citizens to express their views into a microphone. According to Hagabimana, in Rwandan culture, people are not always enthusiastic about expressing their opinions, particularly if they are in opposition to official policies. Yet, Salus has been particularly focused on getting into the villages, places where media typically don't bother to go, to get the stories and voices 
not usually represented by media. He says public fear of speaking on the radio is also starting to change.

Hagabimana actually left his position as a journalist with Radio Rwanda, the national public broadcaster, to join the Radio Salus team in a position of the same salary. As the government's radio station, his supervisors often sent journalists to governmentsponsored events and the voice clips they wanted were those from government representatives. He says his stories were often edited to take out anything that might offend "authorities." At Salus, "the context is very, very different" (Hagabimana, interview, 2007).

Beyond programming, Radio Salus is very different from the national public broadcaster. Staff members support each other and work collaboratively to achieve goals. In a traditionally hierarchical culture, particularly in the work environment, Salus staff work in the spirit of a team, rotating supervisory and training responsibilities. Havugimana, the director, seems to have a close relationship with staff, undoubtedly aided by the fact that he was classmates at the school of journalism and communication with both news director Hagabimana and the program director, Emma-Claudine Ntirenganja. Yet, the director also appears to be in touch with the activities of student journalists and takes an active role in training new Salus recruits. 


\section{SUMMARY}

This chapter introduced Radio Salus, the first community and educational radio station in Rwanda. Owned by the university, the station's signal is heard throughout most of the country. Steven Pasternack, a visiting American scholar, was the first to propose that community radio in Butare could play a double role: a practical training ground for student journalists and an alternative voice in Rwandan broadcasting.

With the support of UNESCO, Radio Salus went on-the-air in November 2005. Journalism students participating in Salus produce news, spoken word programs and talk shows in Kinyarwanda, French, English and Swahili. Michelle Betz, through UNESCO, conducted initial radio production trainings. As of 2008, Salus has committed to training students in-house over the course of several months. As the station continues to grow, it's evident that the organization will need to develop participation and training strategies and create guidelines for accessing essential field recording equipment.

Staff, students and EJC faculty are convinced that Salus is contributing to the development of national radio. Maintaining professional standards and autonomy from the university, government and private interests, Salus represents an independent voice on the Rwandan airwaves. The high level of engagement from listeners responding to 
Salus programming through phone calls, emails and texts also demonstrates active public participation and engagement. 


\section{CHAPTER VI}

\section{CONCLUDING DISCUSSION:}

\section{NAVIGATING SALUS'S FREQUENCY}

It's not uncommon for a radio station classified as community or campus to limit

coverage scope to the particular region where main broadcast facility is situated. A radio station operated by a university, in many cases, does not offer coverage beyond the borders of the surrounding community. Radio Salus, on the other hand, identifies, to some extent, as a national broadcaster. Station director Havugimana rejects classifying Salus as a local-Butare focused radio station. He envisions Salus becoming a significant national voice, as well as a recognized media training organization for journalists from around the country. The Radio Saius of the future, in this young radio director's dreams, is based on the American public radio model (Havugimana, interview, 2007).

A shared ideological mission of building a strong foundation for broadcast journalism in Rwanda anchors Salus supporters. Any success achieved by Salus in the national radio market is, in light of the station mandate, a step forward for the country's under-developed media. 
Through daily news production, Salus journalists often engage themes that

challenge current political and social institutions. The majority of news stories discussed in the previous chapter, a representative sample of one week of Salus newscasts, reflect social justice or grassroots initiatives and, as in the story about the genocide survivors fund, question the efficacy of government programs. According to Hagabimana, Salus news coverage is often based on changing aspects of Rwandan society:

You see, a people who is not informed is like a dead people. So, our job, our work is very useful and very helpful for our society. We help to change bad behavior. For example, (regular citizens) can arrive at the office of the mayor and you do not where he is. But you (the journalist) call the mayor and you ask him, 'People are always claiming your office is closed.' And next time, if he used to do it, he changes. And then you ask him, 'people are claiming roads are not good. Why are you not fixing the roads?' I think our job is like a voice for the voiceless. (Hagabimana, interview, 2007)

As this news director argues, Rwandan journalists have a social responsibility to inform the public while also challenging the status quo.

Yet, despite the station's dedication to producing professional journalism that challenges society and enhances public debate, in light of contemporary communication theory, Salus's limited recruitment and training policies are antiquated. The fallacy of identifying as an educational and community radio station, but offering training to only a select few university students, suggests Salus is not actually a participatory organization. 
Current station policies certainly do not align Salus within participatory development communication models. While Salus's reporting will, perhaps, alter perceptions of media in Rwanda, participatory communication for social change, as discussed in chapter two, encourages "people themselves to define who they are, what they want and need, and how they will work together to improve their lives" (Gumucio-Dagron, 2001: xiv). As will be argued, a true participatory model demands involving all "human subjects of social change" in the process of communication, not merely those with the privilege, as in the case of Radio Salus, of studying at the National University of Rwanda.

Salus's national broadcasting vision is limited by financial restraints. The station can adequately cover events in southern Rwandan communities, but the lack of transportation and finances means reporters can't consistently travel to other regions. Havugimana also recognizes the limitations of relying sciely on student reporters when he notes "they are living in the university community, so they don't exactly know about different things in society -- they are not really living in the community" (Havugimana, interview, 2008). One solution is to train and involve Rwandans outside of the university community to report for Radio Salus, transitioning to a more participatory model. 


\section{Learning from Radio Salus}

The failure of some community radio stations in North America has been an inability to agree on a collective vision. A typical example is when volunteers and staff disagree on the level to which local community members can actively participate in a station situated on a university campus. Internal battles can easily overtake morale and threaten group cohesion when the organization lacks an overarching vision.

The significance of developing a straightforward mission statement and related objectives, based on the Salus model, is a clear path community and campus stations in North America could adopt. While the context of Salus's goals are extraordinary, its spirit of having a common vision -- broad in scope, to which a diverse range of participants can contribute -- speaks to the necessity of developing a strong cooperative environment in any healthy community-based organization. Of course, while debate is part of building a cooperative organization, providing a forum for that discussion needs to be part of the station's mission.

Another lesson that the Salus model teaches North American community radio is the significance of journalism skill development. Canadian community-based stations, particularly those without obvious links to journalism schools, often lack the resources to produce local news and in-depth spoken word programs. At CHMA-FM, for instance, 
daily newscasts were compiled by pulling stories from a news agency service, such as BN, for a hefty subscription fee. Needless to say, there was an absence of local news content on the news wire. In 1998, after years of news production in this manner, a board member suggested switching to a more local-focused evening news magazine show (Malloy, correspondence, 2008). The problem, however, was that there was no one qualified to teach basic journalism skills. Over the years, CHMA has invited in journalists to give workshops and sent volunteers and staff to conferences to learn skills to teach others at the station (ibid). Adapting the Salus model would require stations to invest in broadening training to focus on producing local news, a requirement for Canadian community-based campus stations (CRTC 2000-12) ${ }^{12}$.

The Salus model is, perhaps, most immediately applicable in post-conflict situations, especially in societies that have experienced hostile media snvironments. In Kenya, for instance, "vernacular radio" fuelled tensions during the 2007 electoral campaigns through the broadcast of derisive ethnic-based comments (Nairobi Chronicle, 2008). Since Salus emerges from the tragic result of unmitigated hate media in Rwanda,

\footnotetext{
${ }^{12}$ According to the CRTC policy for community-based campus radio stations, a minimum of 25 per cent of the week's programming content must be spoken word programming. While it does not specifically stipulate "news," it does refer to "local information."
} 
an extreme sensitivity is ingrained in the station ethos in which balance and neutrality are expected, without exception, in all station programming. Reporters are trained to uphold this principle and if content is flagged as being particularly sensitive, it is passed by the director and, in some cases, the station's advisory committee before being broadcast.

\section{An Ethos of Cooperation}

Radio Salus's infrastructure is based on a cooperative model in which staff members work together to find solutions to problems. To refocus on how effective a more participatory, community-based inclusive model could be at Radio Salus, the Rwandan government's promotion of cooperatives should be acknowledged. Since 2005, the formation of cooperatives has been a national priority, particularly in the agriculture sector, to pool resources and generate income (The New Times, 2008).

Since 2005 , the cooperative justice system known as gacaca has tried thousands of accused genocide participants in communities across the country. Whereas the traditional justice system would have taken more than a hundred years to try these accused criminals (continuing to burden overcrowded prisons), gacaca courts have carried out trials on a regular basis, coordinated by community members trained to follow a process (National Service of Gacaca Jurisdictions). At the same time, gacaca is a forum 
in which any community member can testify about an alleged crime. On Wednesday mornings, when gacaca is held in Butare, shops and businesses stay closed so that local citizens can have the opportunity to attend the outdoor court (Sallot, conversation, 2008).

Rwandans have proven that, given a cooperative-based, inclusive model, the nation can make significant progress towards reweaving the social, political and economic fabric torn apart in 1994.

\section{Challenges for the Future: Building A Learning Community}

Salus could constitute a collective learning experience that educational theorists

Jean Lave and Etienne Wenger have coined a community of practice. According to

Wenger, not every organization is necessarily a community of practice. There must be ars intentionality shared amongst the members involved in the learning experience. In the case of Salus, that intentionality is the task of operating an educational and community radio station in Rwanda. While the vast majority of participants are Rwandans, many grew up in neighbouring countries such as Uganda, Democratic Republic of Congo and Tanzania. Yet, they are all bound together by a shared "socio-cultural character" in the immediate context of operating a radio station in Rwanda (Lave 54). 
Radio Salus has, in a sense, developed its own training and educational experience, distinct from the school of journalism and communication. According to Lave and Wenger, Salus constitutes a situated learning experience, whereby participants learn by doing. As opposed to learning in a traditional classroom setting where knowledge is often transmitted, then internally assimilated by the learner, a community of practice "concerns the person acting in the world" (Lave \& Wenger 49). They go on to note that "learning in terms of participation focuses attention on ways in which (learning) is an evolving, continuously relational view of persons, their actions, and the world" (ibid $50)$.

There is no doubt that Radio Salus is already a robust community of practice. Since Salus staff and students are collectively responsible for a product - namely, a radio broadcast - they are all practitioners involved in a complex learning experience concerned with a concrete, real world application. A community of practice recognizes that through an individual's membership in a socio-cultural community - thereby becoming a "person-in-the-world" - "broader systems of relations" between newcomers and experienced practitioners take place. This dynamic social interaction between community members is the basis of the learning, not simply the practical task at hand (ibid $34 \& 52)$. 
The outstanding challenge Radio Salus faces in realizing its potential as a full community of practice is its ability to recognize and integrate a learning process at all levels of the radio station. As outlined below, Salus lacks true legitimate peripheral participation, necessary to realize training and learning capacity.

One of the most important components of a community of practice is legitimate peripheral participation - the mode through which new nembers of the community eventually become full participating members. New members of the community must have access to experienced members so that they achieve a broader understanding of their own place in the community. Through peripheral tasks, newcomers become familiar with a community's activities and, through interaction with more experienced members, eventually learn other components of the operation.

After the initial recruitment and training sessions, Salus newcomers are essentially left to their own devices. There is little, if any, formal relationship between the newcomers and the experienced practitioners at Radio Salus. The problem with this, according to Lave and Wenger, is that the lack of interaction closes the possibility for newcomers to move towards full participation in the community and limits individual growth. Peripheral participation gives newcomers the context in which their own work 
fits, and also "suggests an opening, a way of gaining understanding through growing involvement" (ibid 37).

In November 2007, program director Emma-Claudine Ntirenganja coordinated training for secondary (high school) students that gave them research, interviewing skills and on-air experience. It was the first experiment in offering training to students outside NUR. The idea, she says, is to introduce younger students to radio journalism so that as they get older, they realize the importance of what Radio Salus does. (Ntirenganja, interview, 2007).

If these students stay involved with Salus and continue to interact with other community members, they will expand their learning and skill base and eventually become full members of the community of practice.

An impediment towards legitimate peripheral participation is Salus's hesitancy in offering citizens outside the university community the opportunity to be part of the community. When station director Havugimana suggested that offering radio production training to "farmers," would just prove "complicated," he makes a sweeping generalization and discredits a diverse, large population base. 
Clearly, discounting that people outside the university could be contributing members of the Radio Salus community counters the spirit of legitimate peripheral participation. Rather than creating a learning environment that considers the value of all levels of knowledge, Havugimana takes a rather elitist view of learning. As a community and educational radio station, training opportunities should be extended beyond university students.

Building public confidence in radio is one of Radio Salus's stated objectives. Considering the role radio played in the genocide, it is understandable that media literacy should be another priority for Radio Salus (Havugimana, 2007). In this light, involving citizens in the station is the clearest path to media education. This is not to say that every farmer is a journalist, but avenues of learning can be opened to make Radio Salus accessible to a broader cross section of people.

The significant learning, according to Lave and Wenger, doesn't happen in the instructional zone, but in the context of working with others of varying experience levels to complete common goals. Recognizing the web of interdependency between individuals within all levels of the station is part of the evolving cycle of learning in a community of practice. Lave and Wenger describe a "diversified field of relations among old-timers and newcomers and across the various cycles" as encompassing the learning experience. 
Rather than an expert simply instructing a beginner, learning takes place between all levels of participants (Lave \& Wenger 56-7).

At this stage, Salus is still nailing down a formal training structure for new recruits. Yet, since 2005 when the station went on air, it's been evident that learning continues to take place within all levels of the organization. With the 2007-08 training of first-year students, Havugimana stated that it's in the interest of the station to train them, so that new trainees will become volunteers and eventually train others (Havugimana, 2008). It's an awareness of the varied cycles of training and learning transpiring in an organization that might be key to sustainable, vibrant development within an organization.

At Radio Salus, this exchange of learning could become part of the organization's teaching ethos and culture. While the station is taking steps in facilitating this kind of learning, particularly with the in-house training sessions, the community of practice model could provide some theoretical guidelines. In particular, how can Salus be certain that newcomers are "moving towards full participation" (Lave \& Wenger 29) within the organization, rather than falling between the cracks after initial orientation and training? A community of practice model must be formalized and institutionalized at Radio Salus to make full value of its attributes. The idea of legitimate peripheral participation - 
that current "old-hands" must train new members of the learning community is essential. Naming the idea legitimizes it and helps promote a positive, cooperative learning environment in which knowledge is not hoarded by experts, but is instead shared among as many people as possible.

Without a reflection on the value of collective learning exchanges such as in the community of practice model, skilled participants don't recognize the necessity of sharing the knowledge they've acquired. Some second-year students at Salus become impatient with first-year students and tend towards editing the story themselves, rather than taking time to actually show the novice the steps. This is ironic considering that just ten months previous, someone took the time to teach this second year student! By instilling a sense of responsibility to train, teach and share resources among all levels within the organization, Radio Salus can move towards a more participatory model. Becoming more participatory could mean including more people from outside the university community or expanding on current levels and cycles of member involvement. For instance, discussions and decisions about policies such as gender balance, programming changes, and access to equipment are important areas that affect all station members. If these discussions are taking place at all, they are not held in an open and inclusive forum. 
The manner in which EJC curriculum will be incorporated within Radio Salus

remains to be seen. EJC is seeking to reach a formal agreement with Radio Salus in 2009.

This marks the first time students in all of the school's radio production courses will be required to do a practicum at Salus, as laid out by EJC faculty in Appendix D. While there will be growing pains due to greater influxes of students to train, this new relationship could curb the class absenteeism issue because it would give students Salus experience as part of their course work, as opposed to competing with it. A bigger question is how the school's education philosophy will intersect with a more hands-on training approach at Salus. If EJC deputy director Margaret Jjuuoko's vision is an indicator, the transition towards practical skill training should be relatively smooth: My philosophy is that at the university level you don't teach anyone anything. You just help them develop academically. So, in doing so, you need to keep on encouraging them to discover things by themselves. That mainly concerns the theoretical courses. You know, where students will indulge in their own debate and discussions, they will discover new concepts, new issues, and to be able to conceptualize them based on their already existing theory. When it comes to practical courses, you just need to give students basics. Just a few guidelines, a few tips and you will be amazed at how students can be innovative. (Jjuuko, interview, 2007)

That said, both professors and Radio Salus staff must facilitate practical learning experiences for journalism students. Without committed and conscientious guides, the communities of practice model falls apart because, put simply, apprentices need teachers. 
Speaking of teachers, Canadian journalists continue to play a significant role in guiding EJC students. Allan Thompson, Carleton University journalism professor and founder of media development non-profit Rwanda Initiative, says the project's goal has always been to build the university's capacity to train its own teachers. Sending Canadian journalists to teach courses at EJC, he says, is intended to "strategically create a dynamic that forces (EJC) to build capacity" (Thompson, conversation, 2008). The capacity the Rwanda Initiative is a partner in developing is, ultimately, a sustainable way for EJC to recruit and support experienced Rwandan media professionals to teach university-level journalism and communications courses. Currently, EJC is dependent on a steady stream of Canadian journalists to teach the majority of courses in the curriculum. Since 2006, there have been more than fifty visiting Canadian journalists teaching courses at EJC.

Thompson emphasizes co-teaching as a method of building EJC's teaching capacity. By pairing experienced Rwandan journalists with Canadian teachers for the duration of a course, EJC can begin to develop a pool of professionals with teaching experience. One possible problem with this scenario is that many of the visiting Canadians are professional journalists who lack teaching experience or an understanding of education principles and technique. They may be able to intuitively teach what they know - journalism - but may not be able to teach how to teach. 


\section{AFTERWORD}

The tragic missteps of Rwandan radio in 1994 still resonate within radio stations throughout the country almost fifteen years later. President Paul Kagame's government keeps a close watch on the activities of media and, suffice to say, journalists are not always given impunity by a professional duty to report the truth. While in one breath Kagame declares Rwandan media development is of national importance, in another breath he fires a national newspaper editor. The reason? Kagame deemed a front-page portrait unflattering (Adams, 2007).

Confronted by unsteady ground, sometimes the best solution is to simply put one foot in front of the other and walk forward, one step at a time. Flanked by the National University of Rwanda and some passionate international journalists, Radio Salus is navigating a new path through previously unchartered territory in Rwandan radio.

Three years of walking has led Salus to an interesting fork in the road. In one direction: an asphalt highway cruised by cars with tinted windows is the official route to Kigali. In the opposite direction: a winding dirt road broken in by years of people walking from their villages into town. Should it choose to continue wandering down this path, Salus will maintain its unique position as the radio station that seeks the stories not 
heard on the private airwaves. By telling these stories well, the station becomes not only a voice within Rwanda, but stands as a new paradigm for community radio internationally.

Salus director Havugimana measures the impact of Salus's journey by its ability to reach the people who believed themselves too remote to matter: "In the south of Rwanda, they thought radio was just for people in Kigali, like the ministers." Now, when villagers have a meeting to discuss issues significant to their community, they have a voice through a Salus reporter who arrives with a recorder by bicycle, by motorcycle taxi, by bus, or by foot.

So what?

So what if a women's group discussion is recorded and broadcast? So what if village whose members are infected with HIV are growing vegetables and leading productive lives? So what if a deaf woman didn't rest until she found a school? So what if a genocide victim found himself living down the street from a perpetrator?

The Radio Salus reporter who pitched an interview about beauty pageants in Rwanda has the answer: "This story has to be told because it's never been told." 


\section{APPENDIX A}

\section{NATIONAL UNIVERSITY OF RWANDA}

\section{RADIO SALUS}

E-mail: radiosalus@nur.ac.rw

Name/Nom:

Surname/Prénom:

Faculté et classe/Faculty and class:

No d'inscription/Registration No:

\section{VOLUNTEER'S RECRUITMENT EXAMINATION \\ EXAMEN DE RECRUTEMENT DES VOLONTAIRES}

1. SOS veut dire "Save Our Souls", Vrai ou Faux? Expliquer

SOS stands for 'Save Our Souls' True or False? Explain 
2. En Angleterre, la minute de silence dure deux minutes, Vrai ou Faux?

In England the minute's silence lasts two minutes, True or False?

3. Les vrais jumeaux n'ont pas les mêmes empreintes digitales, Vrai ou Faux ? Commentez

The real twins don't have the same fingerprints, True or False? Comment a bit

4. Cléopâtre était d'origine égyptienne ou romaine?

Cleopatra was from Egypt or Rome?

5. L'homme n'utilise que $10 \%$ de son cerveau, Vrai ou Faux?

A human being uses $10 \%$ of his brain, True or False?

6. L'ordinateur abîme les yeux, Vrai ou Faux? 
A computer damages your eyes, True or False?

7. Quel est a) Le ministre de 1'information au Rwanda

Who is

The rwandan minister of information

b) le gouverneur de la province de l'Ouest

The eastern province governor

8. Le nom d'opposant Zimbabwéen dont le parti a remporté les élections dans la chambre des députés? 
Name of Zimbabwean opposition leader whose political party won the election lastly in Zimbabwean parliamentary.

Name of the Iranian president

9. Que feriez-vous en premier si les situations suivantes se présentaient en même temps

1. Votre bébé crie

2. Votre téléphone mobile sonne

3. Votre four est prêt et sonne

4. Quelqu'un frappe a la porte

What would you do first if the following occurred simultaneously

1. Your baby is crying

2. Your mobile phone is ringing

3. Your oven is ready

4. Someone is knocking at the door

10. Que signifie les abbreviations suivantes?

What is the meaning of the following

\section{abbreviations?}

1. RIEPA

2. SIDA (as an organization) 
3. CIA

4. ISBN

5. SMS

11. Quelle est la nouvelle devise de l'Université Nationale du Rwanda What is the new motto of the National University of Rwanda

12. Purquoi on dit que la Radio Salus émet sur deux fréquences ? Quels sont-elles?

Why do we say that Radio Salus is broadcasting on two frequencies? What are they?

13. Essaie de définir le journalisme selon toi 
Try to give your own definition of journalism

14. En tant que journaliste que ferais-tu pour augmenter l'audience de la Radio Salus ?

What would you do to increase the number of Radio Salus listeners as a journalist?

15. Quels sont les avantages de l'intégration du Rwanda dans la COMESA ? Au moins deux.

What are the advantages of Rwanda joining COMESA? At least two 


\section{APPENDIX B:}

\section{Gahunda y'ibiganiro (Program schedule)}

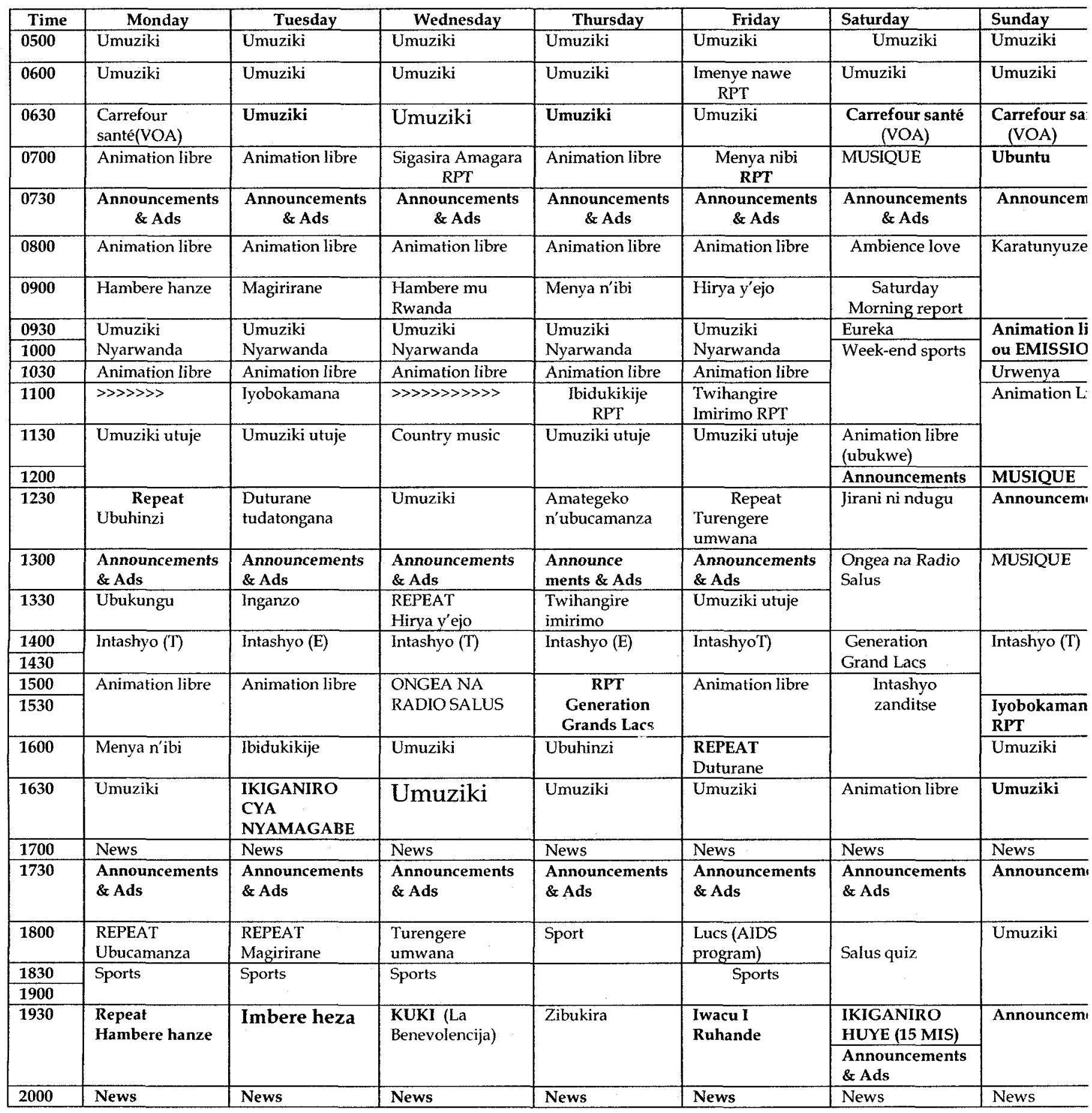




\section{APPENDIX C \\ Newscast (amakuru) November 23, 2007}

Presenter: There are problems in the FARG (Foundation for Genocide Survivors). Some survivors want the law regarding regional selection to be changed.

Clip: The problem is that we are telling him to go where he was when the genocide was happening.

Presenter: This was happening during the selection of survivors at Huye stadium. When leaders and educators know more about genocide, they know how to handle things and how to teach. Genocide happened because of bad leadership. This is why leaders and educators from Nyanza District visited Gisozi Memorial Site today. Oreste Muhizi has more.

Reporter: To visit the genocide memorial site is a sign of unity and reconciliation. This was said by Hycinthe Musanganire, the vice mayor in charge of social affairs in Nyanza district when 160 leaders and educators gathered here.

After being told the history of Rwanda that led the country to genocide in 1994, she asked all Rwandans to fight against genocide.

Musanganire: What I can say, I urge every Rwandan to do what they can to fight against the genocide. This bad history that led the country to genocide, it is outrageous. It is beyond expression, you can't find something to say after what we have seen here. We want our children to inherit a country without divisionism.

This divisionism was taught by white people for many years because they didn't want us to be united. They wanted us to be torn apart. They didn't wish us anything good. So please let us join our forces together and do everything so that this genocide cannot happen again in our country.

Reporter: The Nyanza district authority said the purpose of this visit is to show and explain to leaders and educators of Rwanda because many of them do not know the history or how genocide happened because they were outside of the country in refugee camps. 
For Radio Salus, I'm Oreste Muhizi in Kigali.

Presenter (Ildefonse): Thank you very much.

-- break-

Presenter: The school, Intiganda, has celebrated its 10-year anniversary today.

This school takes care of street kids and at this occasion, they said street kids can change and be good like others and do wonders.

Bernard Byukusenge has more.

--ambient sound - school, clapping--

Reporter: This was at the school Intiganda at the occasion of its 20-year anniversary. This school helps and takes care of street kids. Even though street kids are known For bad behavior like taking drugs and sleeping in the streets and under bridges, it is possible for them to change and do good things.

Benjamin M. got to the school when he was 8 . He is a former street child and now he is graduating from Universite Libre de Kigali in politics.

Benjamin: I was a street kid in Kigali and then I came to Butare to find a better life And we used to sleep in front of Bihira's house, but this house (pointing) was not there before he built these new houses. That's where we cooked and we were cooking on aluminum. It was really bad. And we were drinking rubbing alcohol.

And after I went to the school, I studied and finished senior 5, but I didn't finish senior 6 because I went back in the street because I could not find the rubbing alcohol in the school. But I went back again to the school and they paid for the school and I graduated.

Reporter: Brother Timel of Christian Schools congregation is the man who started this school in 1987.

Timel: Children who is in the street that we commonly call mayibobo is not naturally a mayibobo. He becomes mayibobo because of some circumstances in life.

So that's why it's important to help those kids because they don't have families to take care of them. Maybe their parents divorced, or they have died. But when you are helping these kids, you have to help them but also give them the responsibilities. When I created 
this school, I didn't have the intention to have the school for orphans. I wanted to help those kids to study and go back in their families. Okay, I know we are not saints, one third of the students that we have here go back in the streets. But there are some who stay. And those who stay, I'm sure they won't forget the good things they've learned here.

Reporter: This child went home and encountered problems but when he came back to the school, they didn't accept him. So he went back in the streets.

Unidentified Youth (UY): No, when I went back in the family, my mother died and I told them that and they refused to believe me. Bring my report cards and see if I was not always at the fourth class until the fourth year. So, how could I go back to school when they were only paying for clothes?

And now it's a few months since I dropped out of school, do you think I can go back and study?

Reporter (on tape): But also the school fees?

UY: Was I eating?

Reporter: So why didn't you tell them those problems?

UY: I told them but they didn't want to believe me.

Reporter: For this matter, the school authority says it's hard to take care of the street children.

Christine Mukakabayiza is the head mistress of the school and she says her school tried but what discourages them is that they still see a lot of children in the streets.

Christine: There are some kids that come and we try them for one month or two, but they fail to leave their bad behaviors. So, in that case, we dismiss them. We help these children to stop drinking and drugs. I'm sure some of them stop, but some others fail. Because we don't want those kids to contaminate the other children, we dismiss them. The other reason that can push to dismiss a child is when he wants to fight the teachers. Automatically we dismiss him.

Reporter: Let's remind you that the school Intiganda takes care of street kids and helps them to prepare their future. Now the school 147 students and it built a new school for girls called Nyampinga. For Radio Salus, I'm Bernard... 
--sting--

Presenter: The problem of knowing exactly genocide survivor students to be funded by FARG (Foundation for Genocide Survivors) is still persisting. Some survivors want the law regarding regional selection to be changed.

This was said during the selection of survivors at Huye stadium in Huye district..

Clip: "The problem is that we are telling him to go where he was when the genocide was happening."

Reporter: During this selection there has been a problem of a child called Patrick Byiringiro from Mbazi sector. The region that he comes from, they don't recognize him as a genocide survivor. He's sixteen now and he was three when genocide took place.

Patrick was once on the list of students who were eligible in this same region.

But why is now he Patrick not eligible.

Mukabarinda Marie Alice was the FARG representative during this time.

Marie Alice: The fact I was a FARG representative does not mean that we could accept. To put him on the list because it said he lived with his mother during the genocide. And before we put a child on the list, we have to be sure of the place where he was hiding and how he was hunted.

Reporter: The authority that deleted Patrick from the list because they say they don't know where he was hiding and says he was living with his mother in Butare. But his uncle Filicien Murinda says:

Murinda: They were all in Maraba but when the war broke out they fled to town but they were here in Maraba, our home place.

Reporter: the problem is that during the selection sometimes they can deny children they don't know because it's hard to know a child was little kid during the genocide. It's hard to know a kid who was not in your neighborhood during the war. Byiringiro's uncle thinks this was the same problem for his case. 
Murinda: people who know this are people our neighbors. The problem is that they ask people who are not our neighbors. Those people you see are not our neighbors.

Reporter: Viviane Uwimbabazi is the FARG agent in Huye district, in charge of education. She says that because this problem has been long discussed, they will go in the village to find out.

Viviane: Because it has been long discussed, we decided to go in the village where this child was during the genocide to see if the local authorities recognize him.

Reporter: She added that if they find out that the boy was in the village during the genocide, he will be added on the list. She reminded that the law stipulates that FARG helps poor genocide survivors. And a genocide survivor is someone who was in Rwanda between $1^{\text {st }}$ October 1990 and $31^{\text {st }}$ December, 1994. That person must had been tortured and hunted because of his ethnic group, his ideas or any other related thing.

But being a survivor is personal because you cannot be a survivor, but your brother or your mother is a survivor and so on and so forth.

As Uwimbabazi says, the FARG funded 52, 000 students last year, but now they project the number to be reduced to 49,000 students.

For Radio Salus, I'm Maurice...

---sting -

Presenter - Before we go to international news, we have one more story from Rwanda. Today in Gisagara District, there has been a ceremony of giving certificates to 51 people who learned how to read, count and write.

They were to able to study because of ADEPR in PANA (Program d'Alphebitization National). Bonaventure... has more.

--clapping--

Reporter: Here they were clapping for people who received their certificates. People who got their certificates say it helps them in their daily lives. Hyacinthe Bihoyiki is 45 . She says writing communication is no longer a problem for her. 
Hyacinthe: Now I can read what someone writes to me and write back personally. But before it was hard for me because when someone wrote to me, I could not understand what they wrote to me. And I think its important for me and I urge others who have the same problem that I had to come and study how to write and read and leave that ignorance.

Reporter: For Bigirimana Jean Bosco, a young man of 25, says now reading what is written on the posters wont be a problem any longer as it was before.

Jean Bosco: One day I passed in the wrong way, it was forbidden to pass that way and there was a poster on which it was written 'Birabujijwe guca muri iyi nzira' (it is forbidden to pass here). But I passed there and someone stopped me and asked me why did you pass there? They brought me and showed me the poster. They told me, 'read here'. I said, 'please forgive me, I didn't even go in the first year'. I was lucky because Jesus saved me. They didn't do anything to me. But since then, I decided to go to school.

Reporter: To teach how to read, write and count, ADEPR uses the ladder method, which takes 6 months. At the end of this time, students know how to write, count and read. And they are on the same level as students who have finished their $3^{\text {rd }}$ year primary. Karekezi Yohan, the leader of ADEPR Butare, who handed out the certificates to students, said they did this to help those people and because they think it's ADEPR's responsibility to help them.

Yohan: ADEPR is in Rwanda and as a Rwandan who is patriotic; our leaders think that ADEPR has the responsibility of educating people, body and soul. And we have to know; it's not only ADEPR members that we have to teach, but also other people from different religions. We have to teach them how to write, read and count in order to help them to improve their lives.

Reporter : In his speech, the representative of those who received those certificates, asked ADEPR, not to stop here but to carry on helping them through technical training. The leader of ADEPR in Butare says the process of helping those people has started. Now in Butare, they have opened a technical school for cooking, woodworking, and sewing. 
In two years, 850 students have graduated from the ADEPR program and 1,124 others are still studying. In Kivomo parish that has 4 sectors (names them), They are 12 schools. So far, 173 have graduated from those schools and 257 are still studying.

From Mugombwa, I am Bonaventure Nsabimana for Radio Salus..

Presenter: You are still listening to news on Radio Salus and I'm Ildephonse..

After this sting, we will go to international. 


\section{APPENDIX D}

\section{EJC / Radio Salus Curriculum Plan}

1. Module Code:

2. Module Title: Broadcast Journalism Skills

3. Level: 2 Semester: 2

Credits: 20

4. First vear of presentation: 2009 Administering Faculty: SJC \& Arts and Humanities

5: Pre-requisite or co-requisite modules, excluded combinations

6 Allocation of study and teaching hours See Notes of Guidance

\begin{tabular}{|l|l|}
\hline Total student hours & Student \\
& hours \\
\hline Lectures & 60 \\
\hline Seminars/workshops & 20 \\
\hline Practical classes/laboratory & 20 \\
\hline Structured exercises & 20 \\
\hline Set reading etc. & 20 \\
\hline Self-directed study & 20 \\
\hline Assignments - preparation and writing & 20 \\
\hline Examination - revision and attendance & 200 \\
\hline Other: & \\
\hline
\end{tabular}




\subsection{Brief description of aims and content (not more than five lines)}

To a great extent this module is practically oriented, hence, tailored to provide skills relevant in designing electronic media and communication texts. Practical skills will include, but are not limited to, operating radio and television equipment, writing for the broadcast media, information gathering techniques such as interviewing, and investigative reporting. The module will require individual initiative, including research.

\subsection{Learning Outcomes}

\section{Knowledge and Understanding}

Having successfully completed the module, students should be able to demonstrate knowledge and understanding of:

1) Both conceptual and practical operations of the electronic/broadcast media.

2) The relevance of Radio and television in dissemination of information for development purposes.

3) The how of producing both Radio and TV texts for broadcast and other communication uses.

4) The techniques of gathering information for the production of broadcast texts.

\section{Cognitive/Intellectual skills/Application of Knowledge}

Having successfully completed the module, students should be able to:

Package/produce a variety of texts for the electronic/broadcast media

\section{Communication/ICT/Numeracy/Analytic Techniques/Practical Skills}

Having successfully completed the module, students should be able to: 
1) Package/produce a variety of texts for the electronic/broadcast media

2) To operate Broadcast equipment

3) Present a radio and/or a TV programme

4) Write a script for both radio and television programmes

\section{General transferable skills}

Having successfully completed the module, students should be able to:

Package/produce a variety of texts for the electronic/broadcast media and demonstrate knowledge in the operation of broadcast equipment as well as relevant skills such as writing for broadcast and presentation.

\section{Indicative Content}

1) Intro to TV and Radio News and Current Affairs

2) Writing for the Broadcast Media

3) Presentation and Announcing

4) Computer applications (audio and video editing)

5) Broadcast programme formats

6) The broadcast equipment; radio equipment techniques of gathering information; the radio interview

7) Introduction to the Electronic Media/ Broadband Technology (Broad and Web casting)

8) Practical skills at Salus

\section{Learning and Teaching Strategy}

Our strategy is to provide students with conceptual and practical skills to produce a variety of broadcast texts (radio and television) as well as an understanding of the 
electronic/broadcast media and its relevance and use, in the dissemination of information especially for public consumption.

\section{ASSESSMENT STRATEGY}

a. A practicum at Radio Salus (will include all the techniques necessary for broadcast production).

b. At least up to 5 radio news stories for broadcast on Radio salus

c. A TV and Radio documentary/magazine programme

d. Others as deemed relevant by the facilitator(s).

\section{Assessment Pattern}

\begin{tabular}{|l|c|c|}
\hline Conmponent & Weighting (\%) & $\begin{array}{l}\text { Learning objectives } \\
\text { covered }\end{array}$ \\
\hline In-course assessment: & & $1,2,3,4$ \\
\hline A practicum at Radio Salus & 30 & $2,3,4$ \\
\hline $\begin{array}{l}5 \text { radio news stories for } \\
\text { broadcast }\end{array}$ & 40 & $1,2,3,4$. \\
\hline $\begin{array}{l}\text { Final assessment: TV \& } \\
\text { Radio documentary/magazine }\end{array}$ & 30 & \\
\hline Total & 100 & \\
\hline
\end{tabular}

Put in all learning outcomes

\section{Strategy for feedback and student support during module}
a) Class discussions (both student and teacher-centred)
b) Evaluation forms
c) One-on-one meetings
d) Student discussion Group 


\section{Teaching/Technical Assistance}

1. Projection facilities ( 1 LCD projector, 1 laptop, 1 projection screen).

2. A video camera and audio recorder

Laboratory space and equipment

1. At least 20 broadcast work stations

2. Video and audio editing soft ware

3. Training and airtime at Radio Salus

4. Radio recorders and accessories

5. TV camera and Monitor and accessories

6. Other relevant equipment

\section{Computer requirements}

At least 50 computers with full Internet connection and Microsoft word applications

\section{Others}

$\checkmark$ There is need to purchase some new text books relevant to the Module

$\checkmark$ As will be recommended by the facilitators 


\section{WORKS CITED}

I conducted the following interviews in Rwanda in November \& December 2007:

Terence Muhirwa, production manager, Radio Salus

Eugene Hagabimana, news editor, Radio Salus

Emma Claudine Ntirenganja, program director, Radio Salus

Fabrice Nice Neza, $3^{\text {rd }}$ year NUR engineering student, Radio Salus technician

Aldo Havugimana, station manager, Radio Salus

Pamela Mudakikwa, $1^{\text {st }}$ year EJC journalism student, Radio Salus journalist

Prudent Nsengiyumya, $1^{\text {st }}$ year journalism student, Radio Salus journalist

Carine Umutoni, 4th year journalism student, Radio Salus journalist

Chantal Gakuyano, $1^{\text {st }}$ year journalism student, Radio Salus journalist

Henry Jean de Dieu Uwihanganye, $3^{\text {rd }}$ year science student, Radio Salus journalist

Jean de la Croix Tabaro, $2^{\text {nd }}$ year journalism student, Radio Salus journalist

Margaret Jjuuko, EJC broadcast journalism professor

Interviewed in Rwanda in June and July 2008:

Aldo Havugimana

Jeff Sallot, Canadian journalist and Carleton University professor

Dominic Ndhura, Director of EJC

The following interviews and conversations were conducted in Canada in 2007 \& 2008:

Blythe McKay, Development Communication Coordinator, Developing Countries Farm

Radio Network

Gerardo Reyes Chavez, co-founder, Radio Consciencia, Immokalee, FLA

Allan Thompson, founder, Rwanda Initiative, Ottawa, On

Freya Zaltz, National Campus/Community Radio Association (February 2007)

Melissa Kaestner, NCRA (February 2007)

Interviews conducted through correspondence:

Michelle Betz, media consultant, Salus international trainer (July 2008)

Pierre Malloy, station manager, CHMA-FM radio (September 2008) 


\section{TEXTS}

Alia, Valerie. "Indigenous Radio in Canada" in Crissell, Andrew, ed. More than a music box: radio cultures in a multi-media world. New York: Berghahn Books, 2004.

Adams, Claude. "Are We Aiding A Brutal Censor? The media experts we send to Rwanda: teachers or tools?" The Tyee. 5 Sept. 2007 http://thetyee.ca/Mediacheck/2007/09/05/Kagame/

AMARC "What is community radio?" http://www.amarc.org/amarc/ang/

Augaitis, Diana and Lander, Dan, eds. Radio Rethink. Art, Sound, Transmission. Bnaff Centre: Walter Phillips Gallery, 1994.

Bourgault, L.M. Mass media in sub-Saharan Africa. Indianapolis: Indiana University Press, 1995.

Chalk, Frank. "Intervening to Prevent Genocidal Violence: the Role of the Media" in ed., Allan Thompson, The Media and The Rwanda Genocide. IDRC, 2007.

Curran, James \& Park, Myung-Jin. De-Westernizing media studies. London; New York: Routledge, 2000.

CRTC 2000-12 community-based campus policy http://www.crtc.gc.ca/archive/ENG/notices/2000/ PB2000-12.htm

\section{CRTC Decisions} http://www.crtc.gc.ca/archive/ENG/Decisions/2007/db2007-376.htm http://www.crtc.gc.ca/archive/ENG/notices/2000/PB2000-12.htm

Des Forges, Alison. "Calls To Genocide: Radio in Rwanda, 1994" in Allan Thompson, ed. The Media and the Rwanda Genocide. IDRC, 2007.

Dewey, John. Democracy and Education. Kessinger Publishing, 2004. 
Downing, John D.H. Radical Media: The Political Organization of Alternative Communications. South End, 1984.

Downing, John D. H. Radical Media: Rebellious Communication and Social Movements. Sage Publications, 2001.

Dunifer, Stephen and Sakolsky, Ronald, eds., Seizing The Airwaves: A Free Radio Handbook. San Franscico: AK Press, 1998.

Ellis, Donald G. Transforming conflict: communication and ethnopolitical conflict. Lanham, Md.: Rowman \& Littlefield, 2006.

Fairchild, Charles. Community Radio and Public Culture. Hampton Press: Creskill,NJ, 2001 .

Fardon, Richard \& Furniss, Graham, ed. African Broadcast Cultures: Radio in Transition Oxford: James Currey Publishers, 2000.

Faber, B.D. Community Action and organization change: Image, Narrative, Identity. Southern Illinois University Press, 2002.

Frohardt, Mark \& Temin, Jonathan. "The Use and Abuse of Media in Vulnerable Societies" in Allan Thompson ed., The Media and The Rwanda Genocide. IDRC. 2007.

Fuller, Linda K., ed. Community Media, International Perspectives. Palgrave MacMillan, 2007.

Fraser, C., \& Restrepo-Estrada, S. Community radio for change and development. Development. Unesco, 2002.

Fraser, C., \& Restrepo-Estrada, S. Community Radio Handbook. UNESCO, 2001.

Kabanda, Marcel. "Kangura: the Triumph of Propaganda Refined" in Allan Thompson ed., The Media and the Rwanda Genocide. IDRC, 2007. 
Girard, Bruce, Ed. A Passion For Radio: Radio Waves and Community. Black Rose Books, 1992.

Gourevitch, Philip. We Wish to Inform You Tomorrow We Will Be killed With Our Families: Stories from Rwanda. Picador: New York, 1998.

Gumucio-Dagron, Alfonso and Thomas Tufte, Communication for Social Change: Anthology: Historical and Contemporary Readings. New Jersey: Consortium for Communication for Social Change, 2006.

Gumucio-Dragron A. Making Waves: Participatory Communication for Social Change. New York: Rockefeller Foundation, 2001.

Halleck, D.D. Handheld Vision: The Uses of Community Media. New York: Fordham University Press, 2001.

Haloun, C., ed. Habermas and the Public Sphere. Cambridge: MIT Press, 1993.

Hilmes, Michele and Loviglio ,Jason, eds. Radio Reader- Essays in the Cultural History of Radio. Routledge: London, New York, 2002.

Howley, Kevin. Community media: people, places, and communication technologies. New York: Cambridge University Press, 2005.

Jankowski, N. "Community Media Research: A quest for theoretically grounded models". The Public, Vol. 10, no. 1: 5-13, 1995.

Kamilindi, Thomas. "Journalism in a Time of Hate Media" in Allan Thompson ed., The Media and the Rwanda Genocide. IDRC, 2007.

Lave, Jean \& Wenger, Etienne. Situated Learning: Legitimate Peripheral Participation. Cambridge University Press, 1991.

Land, J. Active Radio: Pacifica's Brash Experiment. Minneapolis: University of Minn. Press, 1999. 
Leishman, Joan. Personal correspondence to Dominic Nduhura, director of EJC. June 2008.

Lewis, P., ed. Alternative Media: Linking Global and Local. Paris: UNESCO, 1993.

Lewis, Peter M. and Jones, Susan, eds. From the margins to the cutting edge: community media and empowerment. Creskill: Hampton Press, 2006.

Li, Darryl. "Echoes of Violence: Considerations on Radio and Genocide in Rwanda" in Allan Thompson ed., The Media and the Rwanda Genocide. IDRC, 2007.

Libero, Felix. Community Broadcasting: Concepts \& Practice in the Philippines. Singapore: Eastern University Press, 2004.

Maslog, C. C., R.L. Navarro, L.N., Tabing, and L.V. Teodoro, eds. Communication for people power: An introduction to community communication. Quezon City: Phillipines, UNESCO- TAMBULI Project, 1997.

Maughan, Chris. The New Times. 8 December, 2007 http://allafrica.com/stories/200712100331.html

McChesney, Robert W. Rich Media, Poor Democracy: Communication Politics in Dubious Times. Champaign, Il: University of Illinois Press, 2000.

McChesney, Robert W. "What is the special significance of community media to civil society?". Media Development, Issue no. 4 http://www.wacc.org.uk/publications/md/md2002-4/comm-media.html

McKay, Blythe. Enhancing Community Over The Airwaves: Community Radio In A Ghanian Fishing Village. University of Guelph: Unpublished Thesis, 2003.

Melkote, Srinivas R. \& Steeves, Leslie H. Communication for Development in the Third World. New Delhi: Sage Publications, 2001. 
Monasebian, Simone. "The Pre-Genocide Case Against Radio-Television RadioTelevision Libre des Milles Collines" in Allan Thompson ed., The Media and The Rwanda Genocide. IDRC, 2007.

Myers, Mary. The Promotion of Democracy at the Grassroots: The Example of Radio in Mali. Frank Cass Journal, Vol. 5, No. 2. London, 1998.

Milam, Lorenzo W. Sex \& Broadcasting: A Handbook for starting a radio station for the community. Los Gatos: KTAO, 1972.

Nambi, Irene. "Rwanda: Rwanda's Cooperative Strategy Against Poverty" in The New Times, 22 July, 2008. http://allafrica.com/stories/200807220117.html.

Nairobi Chronicle: "Vernacular radio fuelled ethnic clashes". 4 August, 2008. http://nairobichronicle.wordpress.com/2008/08/04/vernacular-radio-fuelledethnic-clashes/

National Service of Gacaca Jurisdictions: Overview of gacaca process. http://www.inkiko-gacaca.gov.rw/En/Generaties.htm

Okigbo, Charles, ed. Media and Sustainable Development. Nairobi: African Council for Communication Education, 1995.

Ojo, Tokunbo. "Old Paradigm and Information \& Communication Technologies for Development Agenda in Africa" in Journal of Information Technology Impact. Vol. 4, No. 3, 139-150, 2004.

Pasternack, Steven. Training Future Lecturers for the National University of Rwanda's School of Journalism and Communication. UNESCO, 2003.

Prometheus Radio Project. "Low Power Signals: Special Interest Noise". http://prometheusradio.org/content/view/306/266/

Prunier, Gérard. The Rwanda Crisis: History of a Genocide. London: Hurst, 2005. 
Radio Salus. Outline, objectives and promotional materials Butare, 2007.

Rennie, Ellie. Community Media: A Global Introduction. Rowman \& Littlefield, 2006.

Rodríguez, Clemencia. Fissures in the Mediascape: An International Study of Citizens' Media. Cresskill, NJ: Hampton Press, 2001.

Servaes, Jan. "Communication for Development in a Global Perspective" in Media and Sustainable Development. Nairobi: African Council for Communication Education, 1995.

Servaes, Jan. Communication for Development: one world, multiple cultu: Jersey: Hampton Press,1999.

Sim. Alex. R. "The Farm Radio Story". http://www.uoguelph.ca/ snowden/frf_story.html

Starr, J.M. Air Wars: The Fight to Reclaim Public Broadcasting. Boston, Beacon Press, 2000

Strauss, Neil and Mandle, Dave, eds. Radio Texte (e). Columbia University: Semiotext, 1993.

Thompson, Allan, ed. The Media and the Rwanda Genocide.

London; Ann Arbor, MI: Pluto Press; Kampala, Uganda: Fountain Publishers; Ottawa: International Development Research Centre, 2007.

United Kingdom, Department of Culture, Sport and Media http://www.culture.gov.uk/what_we_do/Broadcasting/QuickLinks/FAQs/what_is _community_radio.htm

Waldorf, Lars. "Censorship and Propaganda in Post-Genocide Rwanda" in ed., Allan Thompson, The Media and The Rwanda Genocide. IDRC, 2007.

Warnock, Kitty. DTR Radio Listening Clubs, Zambia: Impact Evaluation Report. Panos South Africa, 2001. 
Wilkins, Karin Gwinn, ed. Redeveloping Communication for Social Change: Theory, Practice, and Power. Oxford: Rowan \& Littlefield Publishers, 2007.

- Evening newscasts 'Amakuru', 'week of 10/11/07, translated from Kinyarwanda to English 